\title{
The Therapeutic Effectiveness of Delayed Fetal Spinal Cord Tissue Transplantation on Respiratory Function Following Mid-Cervical Spinal Cord Injury
}

\author{
Chia-Ching $\operatorname{Lin}^{1} \cdot$ Sih-Rong Lai $^{1} \cdot$ Yu-Han Shao ${ }^{1}$ - Chun-Lin Chen ${ }^{1,2}$. \\ Kun-Ze Lee ${ }^{1,2,3,4,5}$ (i)
}

Published online: 17 January 2017

(C) The American Society for Experimental NeuroTherapeutics, Inc. 2017

\begin{abstract}
Respiratory impairment due to damage of the spinal respiratory motoneurons and interruption of the descending drives from brainstem premotor neurons to spinal respiratory motoneurons is the leading cause of morbidity and mortality following cervical spinal cord injury. The present study was designed to evaluate the therapeutic effectiveness of delayed transplantation of fetal spinal cord (FSC) tissue on respiratory function in rats with mid-cervical spinal cord injury. Embryonic day-14 rat FSC tissue was transplanted into a C4 spinal cord hemilesion cavity in adult male rats at 1 week postinjury. The histological results showed that FSC-derived grafts can survive, fill the lesion cavity, and differentiate into neurons and astrocytes at 8 weeks post-transplantation. Some FSC-derived graft neurons exhibited specific neurochemical markers of neurotransmitter (e.g., serotonin, noradrenalin, or acetylcholine). Moreover, a robust expression of glutamatergic and $\gamma$-aminobutyric acid-ergic fibers was observed within FSC-derived grafts. Retrograde tracing results indicated that there was a connection between FSC-derived grafts and host
\end{abstract}

Kun-Ze Lee

kzlee@mail.nsysu.edu.tw

1 Department of Biological Sciences, National Sun Yat-sen University, Kaohsiung, Taiwan

2 Doctoral Degree Program in Marine Biotechnology, National Sun Yat-sen University and Academia Sinica, Kaohsiung, Taiwan

3 Center for Neuroscience, National Sun Yat-sen University, Kaohsiung, Taiwan

4 Institute of Medical Science and Technology, National Sun Yat-sen University, Kaohsiung, Taiwan

5 Department of Biomedical Science and Environmental Biology, Kaohsiung Medical University, Kaohsiung, Taiwan phrenic nucleus. Neurophysiological recording of the phrenic nerve demonstrated that phrenic burst amplitude ipsilateral to the lesion was significantly greater in injured animals that received FSC transplantation than in those that received buffer transplantation under high respiratory drives. These results suggest that delayed FSC transplantation may have the potential to repair the injured spinal cord and promote respiratory functional recovery after mid-cervical spinal cord injury.

Keywords Cervical spinal cord injury $\cdot$ Fetal spinal cord tissue $\cdot$ Transplantation $\cdot$ Phrenic $\cdot$ Respiration

\section{Introduction}

Inspiration is generated by contraction of the diaphragm, the primary inspiratory muscle, which is innervated by the phrenic nucleus located at the third to sixth segments of the cervical spinal cord $[1,2]$. Phrenic motoneurons receive inspiratory impulses from the rostral ventral respiratory group in the brainstem [3-5]; therefore, mid-cervical spinal cord injury (SCI) would interrupt this bulbospinal respiratory pathway and directly compromise the phrenic motoneurons. Patients with cervical SCI usually require mechanical ventilation to maintain essential respiratory function [6, 7]. However, long-term mechanical ventilation is associated with increased risk of several respiratory complications, such as pulmonary fibrosis, pneumonia, and aspiration [6-8]. Although weaning from the ventilator is possible if some descending respiratory pathways have been preserved to enable partial activation of respiratory muscles, poor respiration is still exacerbated by atelectasis and chest muscle spasticity, which reduce the compliance of the lung and chest wall $[6,9]$. Therefore, the development of effective therapies to improve respiratory function 
after cervical SCI is a high priority for both basic scientists and clinicians.

Cellular replacement therapy for treatment of SCI has been studied for several decades. A variety of cell types (e.g., Schwann cells, olfactory ensheathing cells, neural stem/ progenitor cells, and bone marrow stromal cells) have been transplanted into the injured spinal cord [10-15]. The goal of cellular transplantation is to replace the lost neural cells and reconnect the segmented spinal cord. In addition, the transplanted cells may have the potential to modulate the microenvironment of the injured spinal cord to support cell/axon growth and/or prevent secondary injury cascades (i.e., inflammation) [16-18]. It has been shown that grafts derived from the fetal spinal cord (FSC) contain lineage-restricted precursors (e.g., cells with a predetermined fate of motoneurons, interneurons, and glia cells), as well as residual populations of stem cells [19-21]. Moreover, FSC tissue has a relatively intact scaffold (i.e., 3-dimensional structure) to support survival, differentiation, and attachment of transplanted cells [22]. Several studies have shown that transplantation of FSC can effectively fill the spinal lesion cavity, repair the spinal circuit, and promote motor functional recovery [22-25]. Our previous study also provided evidence showing FSC can develop into interneuronally enriched grafts following acute transplantation into the upper cervical lesion cavity [20, 26]. These results suggested that FSC-derived grafts may serve as a critical experimental paradigm for investigating the therapeutic strategy of neuronal transplantation following SCI. Accordingly, the goal of the present study was to investigate the therapeutic effectiveness of delayed transplantation of FSC on the recovery of respiratory function in adult rats with mid-cervical spinal hemisection. Our goals were to 1) evaluate the viability of FSC tissue in injured cervical spinal cord; 2) identify the differentiation status and neurochemical phenotypes of FSC-derived graft cells; 3) examine the connectivity between the graft and the host phrenic motor system; and 4) investigate the influence of FSC transplantation on respiratory function.

\section{Methods}

\section{Ethical Approval}

All experimental procedures were approved by the Institutional Animal Care and Use Committee at the National Sun Yat-sen University and performed in accordance with the guidelines for experimental animals.

\section{Animals}

The present study used 68 adult male Sprague-Dawley rats purchased from BioLasco Taiwan Co., Ltd (Taipei, Taiwan).
The animals received either $\mathrm{C} 3 / 4$ laminectomy surgery (i.e., uninjured group, $n=8$ ) or unilateral hemisection at the fourth cervical spinal cord $(\mathrm{C} 4 \mathrm{Hx}, n=60)$. $\mathrm{C} 4 \mathrm{Hx}$ animals then received transplantation of Hank's balanced buffer solution (HBSS) (C4Hx + HBSS group, $n=10)$, normal FSC tissue (C4Hx + nFSC group, $n=8$ ), or FSC tissue expressing green fluorescence protein (GFP) (C4Hx + GFP-FSC group, $n=42)$ at 1 week postinjury. An additional 3 male Sprague-Dawley rats that expressed GFP were obtained from pregnant Sprague-Dawley rats mated with a genetically modified Sprague-Dawley rat (SD-Tg UBC-emGFP 18Narl) purchased from the National Laboratory Animal Center (Taipei, Taiwan). These GFP rats were received $\mathrm{C} 4$ hemisection at age of 8 to 9 weeks and then received normal FSC tissue transplantation at 1 week postinjury (GFP-C $4 \mathrm{Hx}+\mathrm{nFSC}$ group).

\subsection{SCI}

The animals were anesthetized with xylazine $(10 \mathrm{mg} / \mathrm{kg}$, s.c., Rompun ${ }^{\circ}$; Bayer, Leverkusen, Germany) and ketamine (140 mg/kg, i.p., Ketalar®; Pfizer, New York, NY, USA) at 8 to 9 weeks of age. After disappearance of the toe-pitch withdrawal reflex, animals received a dorsal cervical incision followed by C3-C4 laminectomy. A lesion cavity at the left C4 spinal cord was created by incision and aspiration using a micropipette connected to a suction pump (TM-330; TOMIN, New Taipei, Taiwan). The dura was sutured with 10-0 nylon (UNIK) sutures, and the overlying muscles and skin were closed with 4-0 chromic (UNIK) and 4-0 nylon (UNIK) sutures, respectively. The animals then received subcutaneous injections of yohimbine (1.2 mg/kg; Tocris, Bristol, UK) and Lactated Ringer's solution ( $5 \mathrm{ml}$; Nang Kuang Pharmaceutical Co., Ltd, Tainan, Taiwan) to reverse the action of xylazine and prevent dehydration, respectively. A single bolus injection of buprenorphine $(0.03 \mathrm{mg} / \mathrm{kg}$, s.c.; Shinlin Sinseng Pharmaceutical Co., Ltd, Taoyuan, Taiwan) was provided for analgesia after awakening from anesthesia. A 1 to $3 \mathrm{ml}$ oral Nutri-cal supplement (EVSCO Pharmaceuticals, Fort Worth, TX, USA) and $5 \mathrm{ml}$ Lactated Ringer's solution injection (s.c.) were provided daily until recovery of volitional eating and drinking.

\section{FSC Transplantation}

Uninjured and $\mathrm{C} 4 \mathrm{Hx}$ animals were anesthetized with xylazine (10 mg/kg, s.c.) and ketamine (140 mg/kg, i.p.) at 1 week postspinal cord surgery. The cervical spinal cord lesion cavity in C4Hx animals was exposed for HBSS, nFSC, or GFP-FSC transplantation. Normal FSC (i.e., non-GFP-expressing) was obtained from pregnant Sprague-Dawley rats at 14 days of gestation, purchased from BioLasco Taiwan Co., Ltd., Taipei, Taiwan GFP-expressing FSC (GFP-FSC) was obtained from a pregnant Sprague-Dawley rat that was mated with a genetically modified Sprague-Dawley rat (SD-Tg UBC-emGFP 
18Narl) purchased from the National Laboratory Animal Center (Taipei, Taiwan). The pregnant rat was anesthetized with xylazine (10 mg/kg, s.c.) and ketamine (140 mg/kg, i.p.) followed by the laparotomy. The embryos were exposed and then removed from the placenta and placed in HBSS. GFP-positive embryos were selected by observing expression of green florescence using Micescope (X-Loupe GFP version; Lumos Tech, Co., Ltd, Taipei, Taiwan). nFSC was removed and sectioned into $\sim 1$ to $2 \mathrm{~mm}$ segments and placed into the C4 lesion cavities of $\mathrm{C} 4 \mathrm{Hx}+\mathrm{nFSC}$ or GFP-C4Hx $+\mathrm{nFSC}$ group. GFP-FSC tissue was transplanted into the lesioned spinal cord of C4Hx + GFP-FSC animals. HBSS $(2 \mu \mathrm{l})$ was injected into the lesion cavity of $\mathrm{C} 4 \mathrm{Hx}+\mathrm{HBSS}$ group. The suture procedure and postsurgical animal care protocol were similar to those described in the SCI section.

\section{Respiratory Behavior Measurements in Unanesthetized Animals}

The respiratory behaviors (e.g., respiratory frequency, tidal volume, and minute ventilation) of uninjured, $\mathrm{C} 4 \mathrm{Hx}+\mathrm{HBSS}$, $\mathrm{C} 4 \mathrm{Hx}+\mathrm{nFSC}$, and $\mathrm{C} 4 \mathrm{Hx}+\mathrm{GFP}-\mathrm{FSC}$ group animals were measured 1 day before transplantation and 1,2, 4, and 8 weeks after transplantation using the whole-body plethysmography system (Buxco® FinePointe Whole Body Plethymography; Data Sciences International, New Brighton, MN, USA). The temperature, humidity, and airflow of the chamber (\#PLY4213, volume: 3.9 1) were calibrated by the standard procedure indicated by the manual. Body temperature was measured on the day of the experiment and the value was imported into the system to calibrate the breathing pattern parameters. The animals were placed into the chamber and exposed to normoxic gas $\left(21 \% \mathrm{O}_{2}, 79 \% \mathrm{~N}_{2}, 2.5 \mathrm{l} / \mathrm{min}\right)$ for $60 \mathrm{~min}$ to obtain baseline recording, followed by $10 \mathrm{~min}$ hypoxic gas $\left(10 \% \mathrm{O}_{2}, 4 \% \mathrm{CO}_{2}\right.$, $86 \% \mathrm{~N}_{2}, 2.5 \mathrm{l} / \mathrm{min}$ ) by flushing the compressed gas mixture into the chamber. The animals were placed back into cages at 10 min after termination of hypoxic challenge.

\section{Phrenic Nerve Recording in Anesthetized Animals}

Bilateral phrenic motor outputs were evaluated in a subset of animals (uninjured, $n=8$; $\mathrm{C} 4 \mathrm{Hx}+\mathrm{HBSS}, n=10$; $\mathrm{C} 4 \mathrm{Hx}+$ nFSC, $n=8$ ) after whole-body plethysmography at 8 to 9 weeks post-transplantation. The animals were anesthetized with urethane (1.6 g/kg, i.p.; Sigma, St. Louis, MO, USA) and rectal temperature was monitored by an electrical thermometer and maintained at $37 \pm 1{ }^{\circ} \mathrm{C}$ by a servo-controlled heating pad (model TC-1000; CWE Inc., Ardmore, PA, USA). The trachea was cannulated with an endotracheal tube (PE-240; Clay Adams, Sparks, MD, USA), and the femoral artery and vein were cannulated with a PE-50 catheter for blood pressure measurement (Transducer: DTX-1; Amplifier: TA-100; CWE Inc.) and paralytic agent administration (pancuronium bromide, $2.5 \mathrm{mg} / \mathrm{kg}$, i.v.; Fresenius Kabi, Port Elizabeth, South Africa). The animal was mechanically ventilated with an oxygen/nitrogen mixture $\left(50 \% \mathrm{O}_{2}\right.$, balance $\left.\mathrm{N}_{2}\right)$ using a ventilator (volume $=7 \mathrm{ml} / \mathrm{kg}$; frequency $=60-70 / \mathrm{min}$, KDS 35; KD Scientific, Holliston, MA, USA). The partial pressure of end-tidal $\mathrm{CO}_{2}\left(\mathrm{P}_{\mathrm{ET}} \mathrm{CO}_{2}\right)$ was monitored by connecting a $\mathrm{CO}_{2}$ Capnogard sensor (Novametrix Medical Systems, Madison, WI, USA) to the expiratory line of the ventilator. The $\mathrm{P}_{\mathrm{ET}} \mathrm{CO}_{2}$ was maintained at $45 \mathrm{mmHg}$ by adjusting the inspired $\mathrm{CO}_{2}$ and the ventilator frequency. A ventral approach was used to expose the bilateral phrenic nerve within the neck region, and the phrenic nerve was then sectioned distally and placed on a monopolar silver electrode (\#782500; A-M System, Sequim, WA, USA). The phrenic nerve activity was recorded using a differential A/C amplifier (Model 1700; A-M Systems) with $1000 \times$ amplification and 0.3 to $10-\mathrm{kHz}$ bandpass filtration. The neural signals were also rectified and smoothed (time constant: $25 \mathrm{~ms}$ ) to quantify the burst amplitude of the phrenic nerve. These physiological signals were digitized by a CED Power 1401 (Cambridge Electronic Design Limited, Cambridge, UK) and stored in a computer.

Three approaches were sequentially applied to increase respiratory drive, using 10-min intervals, each following a 10min stable baseline recording of the bilateral phrenic nerves: 1) bilateral vagus nerves were sectioned at the cervical region to eliminate vagal afferent inputs; 2) hypoxia $\left(12-14 \% \mathrm{O}_{2}\right.$, balance $\mathrm{N}_{2}, 3 \mathrm{~min}$ ) was introduced to activate peripheral chemoreceptors; 3 ) asphyxia was applied by turning off the ventilator for $1 \mathrm{~min}$ to assess the maximum phrenic burst amplitude.

\section{Spinal cord histology}

Animals (uninjured, $n=8$; $\mathrm{C} 4 \mathrm{Hx}+\mathrm{HBSS}, n=10$; $\mathrm{C} 4 \mathrm{Hx}+$ nFSC, $n=8$ ) used to examine the bilateral phrenic bursting were also used to evaluate the viability and differentiation of FSC after transplantation into the lesioned spinal cord. After termination of the neurophysiological recording procedure, the animals were perfused with heparin-saline $(200 \mathrm{ml})$ followed by $4 \%$ paraformaldehyde $(250 \mathrm{ml}$; Alfa Aesar, Ward Hill, MA, USA) and then 10\% sucrose (Sigma) in $4 \%$ paraformaldehyde $(250 \mathrm{ml})$. The spinal cord was removed and its gross anatomy was imaged by stereomicroscope (M80 or M60; Leica, Wetzlar, Germany) connected to a digital camera (EOS 600D; Canon). The cervical spinal cord was dissected and placed in $30 \%$ sucrose in phosphate-buffered saline (PBS; UniRegion Biotech, Taipei, Taiwan). The spinal cord was then cryoprotected and transversely sectioned into $40-\mu \mathrm{m}$ slices using a Cryostat (CM 1850; Leica). Spinal cord sections from a subset of animals (uninjured, $n=2$; C4Hx $+\mathrm{HBSS}, n=7$; $\mathrm{C} 4 \mathrm{Hx}+\mathrm{nFSC}, n=5$ ) were serially mounted on glass slides (S7441; Matsunami Glass Ind., LTD, Osaka, Japan) and stained with cresyl violet (Acros Organics, Geel, Belgium). The morphology of the spinal cord sections were examined 
using an upright microscope (CM850; Leica), and digital images were taken with a digital camera (EOS 600D; Canon, Tokyo, Japan) connected to the microscope. The spinal cord sections from the other animals (uninjured, $n=6$; $\mathrm{C} 4 \mathrm{Hx}+$ HBSS, $n=3$; C4Hx + nFSC, $n=3$ ) were doubleimmunofluorescence stained with a neuron marker [neuronal nuclei (NeuN)] and astrocyte marker [glial fibrillary acidic protein (GFAP)]. The spinal cord sections were immersed in $73 \%$ (10 $\mathrm{min}$ ) and 95\% (10 $\mathrm{min}$ ) alcohol and then washed with PBS $(2 \mathrm{~min})$. The sections were incubated in $3 \% \mathrm{H}_{2} \mathrm{O}_{2}$ for $15 \mathrm{~min}$, re-washed in PBS $(3 \times 5 \mathrm{~min})$, and blocked against nonspecific protein labeling [3\% normal goat serum ( $\# 5425$; Cell Signaling Technology, Danvers, MA, USA) in PBS] for $1 \mathrm{~h}$. After washing by PBS with $0.05 \%$ Tween 20 (Bio Basic Int., Amherst, NY, USA) $(4 \times 5 \mathrm{~min})$, the sections were incubated in primary antibody against NeuN (rabbit anti-NeuN, 1:500, \#12943; Cell Signaling Technology) and GFAP (mouse anti-GFAP, 1:200, \#3670; Cell Signaling Technology) at $4{ }^{\circ} \mathrm{C}$ overnight. On the following day, the sections were washed in PBS with $0.05 \%$ Tween $20(4 \times 5 \mathrm{~min})$, blocked using $3 \%$ normal goat serum $(1 \mathrm{~h})$ and re-washed with $0.05 \%$ Tween $20(4 \times 5 \mathrm{~min})$. The sections were then incubated for $2 \mathrm{~h}$ at room temperature with secondary antibodies Alexa Fluor 594 donkey antirabbit IgG (1:200, \#711-585-152; Jackson ImmunoResearch Laboratories, Inc., West Grove, PA, USA) and Alexa Fluor 488 donkey antirabbit IgG (1:200, \#715-545150; Jackson ImmunoResearch Laboratories, Inc.). The sections were mounted on glass slides and coverslipped with mounting medium containing 4',6-diamidino-2-phenylindole (DAPI) following by washing in PBS with $0.05 \%$ Tween 20 $(4 \times 5 \mathrm{~min})$. Microphotographs were taken with a microscope (BX43; Olympus, Tokyo, Japan) connected to a chargecoupled device [CCD; DS-5Mc (Nikon), Tokyo, Japan].

The normal rats that received GFP-FSC transplantation $(\mathrm{C} 4 \mathrm{Hx}+\mathrm{GFP}-\mathrm{FSC}, n=31)$ and GFP rats that received normal FSC transplantation (GFP-C4Hx $+n F S C, n=3$ ) were systemically perfused with $250 \mathrm{ml}$ heparin-saline followed by $500 \mathrm{ml}$ 4\% paraformaldehyde (Alfa Aesar). The spinal cord was transversely cut into $40-\mu \mathrm{m}$ sections (Vibratome 1000, The Vibratome Co., St. Louis, MO, USA). Each spinal cord tissue section was stained with 2 to 4 types of neural cell markers [NeuN (rabbit anti-NeuN, 1:500, \#12943; Cell Signaling Technology) for neurons; GFAP (mouse anti-GFAP, 1:200, \#3670; Cell Signaling Technology) for astrocytes; ionized calcium-binding adapter molecule 1 (Iba1) (rabbit anti-Iba1, 1: 1000, \#019-19741; Wako Pure Chemical Industries, Ltd., Tokyo, Japan) for microglia; receptor interacting protein (RIP) (mouse antioligodendrocytes, 1:100,000, MAB1580; Merck Millipore Corp., Darmstadt, Germany) for oligodendrocytes] and neurochemical markers [decarboxylase 65 and 67 (GAD) (rabbit anti-GAD, 1:2000, AB1511; Merck Millipore Corp.); serotonin (rabbit antiserotonin, 1:5000, \#20080; ImmunoStar, Hudson, WI, USA); vesicular glutamate transporter 2 (VGLUT2) (goat
anti-VGLUT2, 1:6000, AB2251; Merck Millipore Corp.); dopamine beta hydroxylase (DBH) (mouse anti-DBH, 1:400, MAB308; Merck Millipore Corp.); choline acetyltransferase (ChAT) (goat anti-ChAT, 1:50, AB144P; Merck Millipore Corp.)]. The staining procedure is similar to that described above, except that the normal goat serum was not used for ChAT and VGLUT2 staining. The corresponding secondary antibodies were Alexa Fluor 594 donkey antirabbit IgG (1:200, \#711-585152; Jackson ImmunoResearch Laboratories, Inc.), Alexa Fluor 594 donkey antimouse IgG (1:200, \#715-585-150; Jackson ImmunoResearch Laboratories, Inc.), or Alexa Fluor 647 donkey antigoat IgG (1:200, ab150131; Abcam, Cambridge, UK). The spinal sections were mounted on glass slides and coverslipped with mounting medium containing DAPI. The microphotographs were taken with a microscope (BX43; Olympus) connected to a CCD (DS-5Mc; Nikon).

\section{Retrograde Tracer Application}

A subset of C4Hx + GFP-FSC animals $(n=11)$ were used to examine the connectivity between the graft and the phrenic neural circuits. After whole-body plethysmography measurements at 8 weeks post-transplantation, the animals were anesthetized with xylazine $(10 \mathrm{mg} / \mathrm{kg}$, s.c.) and ketamine $(140 \mathrm{mg} /$ $\mathrm{kg}$, i.p.). A laparotomy was performed and the abdominal muscle was retracted to expose the diaphragm. Monosynaptic retrograde tracer $[40 \mu \mathrm{l} ; 0.05 \%$, cholera toxin subunit B (CT-B) conjugated with Alexa Fluor 594 (C34777); ThermoFisher Scientific, Waltham, MA, USA] $(n=4)$ or trans-synaptic tracer $[1.75 \%$, wheat germ agglutinin (WGA) conjugated with Alexa Fluor 594 (W11262); ThermoFisher Scientific] $(n=7)$ was painted on the bilateral diaphragm $[27,28]$. At 3 days after tracer painting, the animals were anesthetized with urethane $(1.6 \mathrm{~g} / \mathrm{kg}$, i.p.) and perfused with heparin-saline followed by $4 \%$ paraformaldehyde. The $\mathrm{C} 2$ C5 spinal cord was horizontally sectioned into $40-\mu \mathrm{m}$ slices (CM 1850; Leica), mounted on glass slides and coverslipped with mounting medium containing DAPI. The tracer-labeled neurons were observed and imaged by a microscope (BX43; Olympus) connected to a CCD (DS-5Mc; Nikon).

\section{Data Analysis and Statistics}

\section{Viability of $G F P-F S C$}

The viability of GFP-FSC 8 week post-transplantation was evaluated by analyzing the area of GFP-positive tissue in both transverse and horizontal spinal sections of $\mathrm{C} 4 \mathrm{Hx}+\mathrm{GFP}-$ FSC animals. The transverse section with the largest GFPpositive tissue in each animal $(n=31)$ was selected to quantify the area of uninjured side host tissue, injured side spared host tissue, and GFP-positive tissue using ImageJ software (National Institutes of Health, Bethesda, MD, USA). The data 
were expressed as the absolute value (i.e., $\mathrm{mm}^{2}$ ) and a percentage of the uninjured side host tissue.

The GFP-positive area was also quantified at the dorsal, central, and ventral layers of the horizontal spinal cord section $(n=11)$, to examine whether GFP-FSC had evenly filled the lesion cavity. These data were analyzed using a 1-way repeated measures analysis of variance (ANOVA) followed by a Student-Newman-Keuls (SNK) post hoc test.

\section{Differentiation of FSC-Derived Graft}

The area fraction of immunoreactivity of neural markers (i.e., NeuN, GFAP, Iba1, and RIP) within the graft region and uninjured side host gray and white matter was quantified in C4Hx + GFP-FSC animals ( $n=6$ animals for each marker) using ImageJ software. The transverse spinal cord section with the largest GFP-positive tissue of individual marker staining in each animal was selected. The area of the interest (i.e., graft, uninjured side host gray and white matter tissue) was manually selected using the polygon selection tool and the image was then converted to the grayscale image. The threshold detection was adjusted to reveal the pixels reflecting staining of markers and the area fraction of these pixels were determined by the measurement function of the ImageJ software. These data were analyzed by a repeated measures ANOVA followed by a SNK post hoc test.

\section{Respiratory Behavior}

The respiratory behavior data (e.g., respiratory frequency, tidal volume, minute ventilation) were analyzed by FinePointe software (Data Sciences International). These parameters were exported to an Excel file (Microsoft, Redmond, WA, USA) and averaged over $10 \mathrm{~min}$ for the normoxic baseline and over the final 2 min for hypoxic challenge. The data from $\mathrm{C} 4 \mathrm{Hx}+$ $\mathrm{nFSC}$ and $\mathrm{C} 4 \mathrm{Hx}+\mathrm{GFP}-\mathrm{FSC}$ groups were not significantly different; therefore, these 2 groups were combined into a single $\mathrm{C} 4 \mathrm{Hx}+\mathrm{FSC}$ group. The data were then analyzed by 2-way mixed-design ANOVA [factor one: group (e.g., uninjured, C4Hx + HBSS and C4Hx + FSC); factor two: time point (e.g., 1 day before transplantation and 1, 2, 4, and 8 weeks after transplantation)] followed by SNK post hoc test. A linear regression analysis was used to examine the relationship between the respiratory tidal volume and the size of spared host tissue and FSCderived graft in $\mathrm{C} 4 \mathrm{Hx}+\mathrm{FSC}$ animals before and at 8 weeks after transplantation under baseline and hypoxic breathing.

\section{Phrenic Nerve Activity}

The respiratory cycle and phrenic burst amplitude were calculated from the rectified and smoothed phrenic neurogram. The respiratory cycle duration was defined as the period between 2 successive onsets of phrenic bursting, and phrenic burst frequency was determined as 60/respiratory cycle duration. Phrenic burst amplitude was calculated as the difference between the maximal and minimum value of the rectified and smoothed phrenic neurograms within a single neural breath. Data were averaged over $30 \mathrm{~s}$ during baseline, after vagotomy, and the over last $30 \mathrm{~s}$ of hypoxic treatment. The maximum phrenic burst amplitude was assessed during the asphyxic response. Phrenic burst amplitude was expressed in microvolt $(\mathrm{mV})$, the percentage of baseline value $(\% \mathrm{BL})$, and the maximum response during asphyxia (\% max). These data were analyzed using two-way mixed-design ANOVA [factor one: group (e.g., uninjured, $\mathrm{C} 4 \mathrm{Hx}+\mathrm{HBSS}$ and $\mathrm{C} 4 \mathrm{Hx}+\mathrm{nFSC}$ ); factor two: condition (e.g., baseline, vagotomy, hypoxia and asphyxia)] followed by SNK post hoc test.

All data are expressed as the mean \pm SEM. A $p$-value $<$ 0.05 was considered statistically significant.

\section{Results}

\section{Survival of FSC Tissue}

Representative examples of spinal cord gross anatomy and spinal cord sections in uninjured, C4Hx + HBSS and C4Hx + nFSC animals are shown in Figure 1. There was a significant lesion cavity on the injured side (i.e., left) in the $\mathrm{C} 4 \mathrm{Hx}+\mathrm{HBSS}$ animal at 8 weeks post-transplantation (Fig. 1B); however, such a lesion cyst was not observed in the $\mathrm{C} 4 \mathrm{Hx}+\mathrm{nFSC}$ animal (Fig. 1C). In addition, several cresyl violet stained cells were present in the putative graft region (Fig. 1C). Double immunofluorescence staining with NeuN and GFAP demonstrated that NeuN-positive and GFAP-positive cells were predominately located within the gray and white matter, respectively, of uninjured animals (Fig. 2A). Following SCI, GFAP was highly expressed at the boundary between the lesion area and the host spinal cord in both $\mathrm{C} 4 \mathrm{Hx}+\mathrm{HBSS}$ animals and $\mathrm{C} 4 \mathrm{Hx}+\mathrm{nFSC}$ animals (Fig. 2B, C). Moreover, some NeuN-positive cells were detected in the putative graft region in $\mathrm{C} 4 \mathrm{Hx}+\mathrm{nFSC}$ animals (Fig. 2C). These data suggest that the $\mathrm{C} 4$ hemilesion cavity can be filled by the neural cells.

To further identify whether neural cells in the putative graft region were derived from transplanted FSC tissue, the FSCexpressing GFP (i.e., GFP-FSC) was transplanted into the lesion cavity of $\mathrm{C} 4 \mathrm{Hx}$ animals, and FSC-derived tissue was identified by GFP expression. At 8 weeks post-transplantation, GFP-positive signals were detected in the injured-side spinal cords of C4Hx + GFP-FSC animals (Fig. 3A). In the transverse spinal cord sections, there was a mild tissue sparing in the injured side $\left(0.6 \pm 0.1 \mathrm{~mm}^{2} ; 19 \pm 3 \%\right.$ of the contralateral host spinal tissue), suggesting incomplete lesion. However, the lesion cavity could be filled with the GFP-positive tissue (Fig. 3B). The area of GFP-positive tissue was $2.0 \pm 0.2 \mathrm{~mm}^{2}$, which was $75 \pm 9 \%$ of the contralateral host spinal tissue 
Fig. 1 Gross anatomy and transverse section of mid-cervical spinal cord of (A) uninjured, (B) $\mathrm{C} 4 \mathrm{Hx}+$ Hank's buffered saline solution (HBSS), and (C) $\mathrm{C} 4 \mathrm{HX}+$ normal fetal spinal cord (nFSC) animals. Panel (a) presents the dorsal view of the cervical spinal cord. Panels (b) and (c) show the spinal cord section stained with cresyl violet. The putative graft region is labeled by the dashed line in panel $(\mathrm{C}, b)$. Panel (c) is a higher magnification view of the region in panel (b) indicated by the solid line

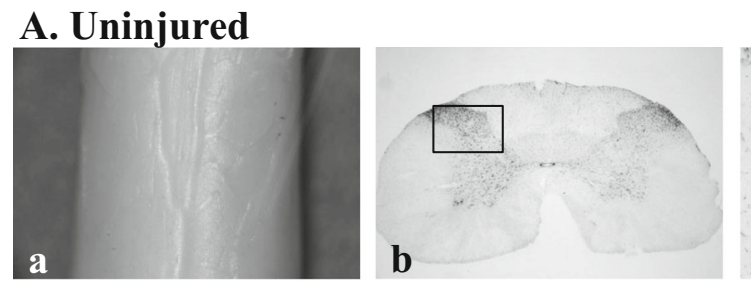

B. C4Hx + HBSS

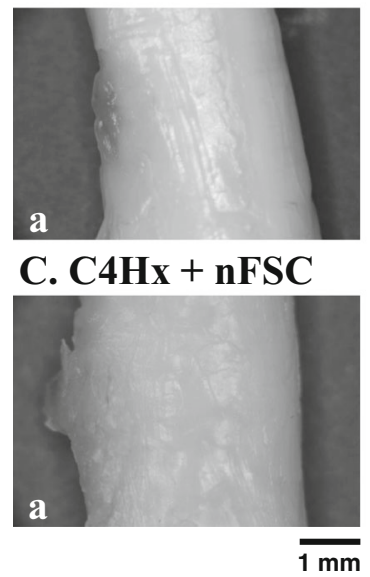

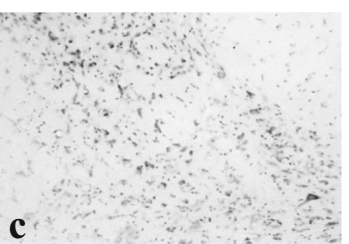

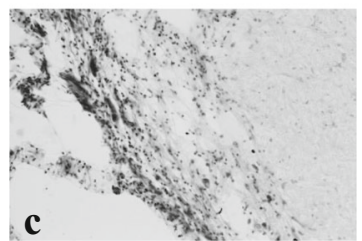

b

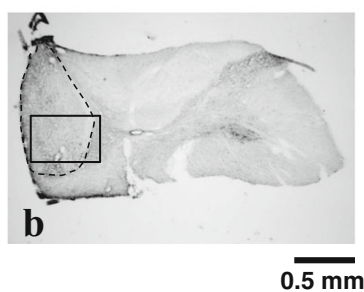

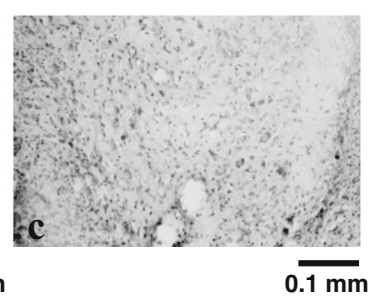

(Fig. 3D). In addition, horizontal spinal sections indicated that the area of GFP-positive tissue was evenly distributed throughout the different layers of the spinal cord (Figs 4A-C and $5 \mathrm{~A}-\mathrm{C})$. Specifically, the areas of GFP-positive tissue were $1.13 \pm 0.23 \mathrm{~mm}^{2}, 1.17 \pm 0.39 \mathrm{~mm}^{2}$, and $1.13 \pm 0.38 \mathrm{~mm}^{2}$ in the dorsal, central, and ventral layers of the spinal cord, respectively.

\section{Differentiation of FSC Tissue}

Four primary neural cell types (e.g., neuron, astrocyte, microglia, and oligodendrocyte) were identified in $\mathrm{C} 4 \mathrm{Hx}+$ GFP-FSC group by examining the expression of NeuN (for neurons), GFAP (for astrocytes), Iba1 (for microglia), and RIP (for oligodendrocytes) (Fig. 6). Transverse spinal cord
Fig. 2 Transverse cervical spinal cord section, double immunofluorescently stained with (a, red) NeuN and (b, green) glial fibrillary acidic protein (GFAP) from (A) uninjured, (B) $\mathrm{C} 4 \mathrm{Hx}+$ Hank's buffered saline solution (HBSS), and (C) $\mathrm{C} 4 \mathrm{HX}+$ normal fetal spinal cord (nFSC) animals. Panel (c) is a higher magnification view of the merged NeuN and GFAP images indicated by the white boxes in panels (a) and (b), respectively

\section{A. Uninjured}
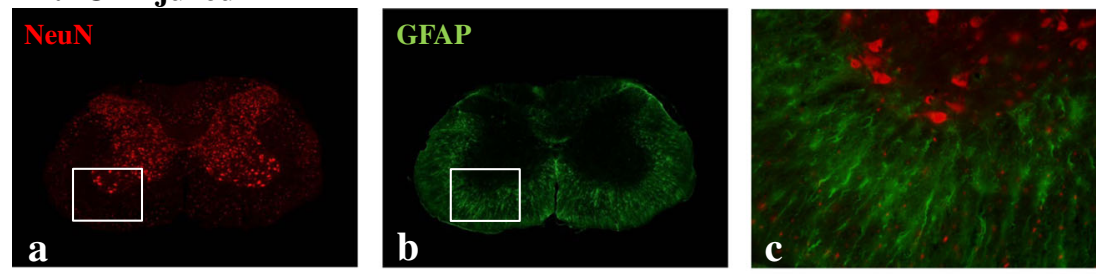

B. $\mathrm{C} 4 \mathrm{Hx}+\mathrm{HBSS}$
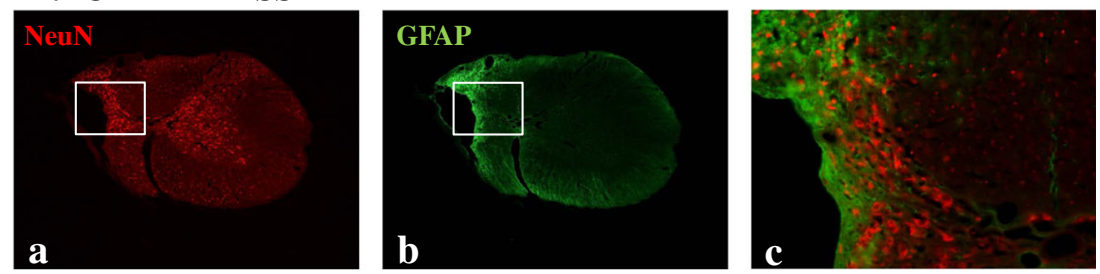

C. $\mathbf{C 4 H x}+$ FSC
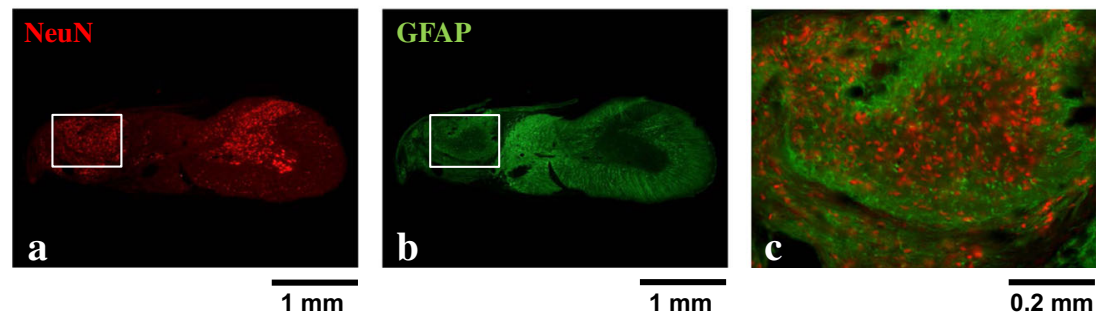

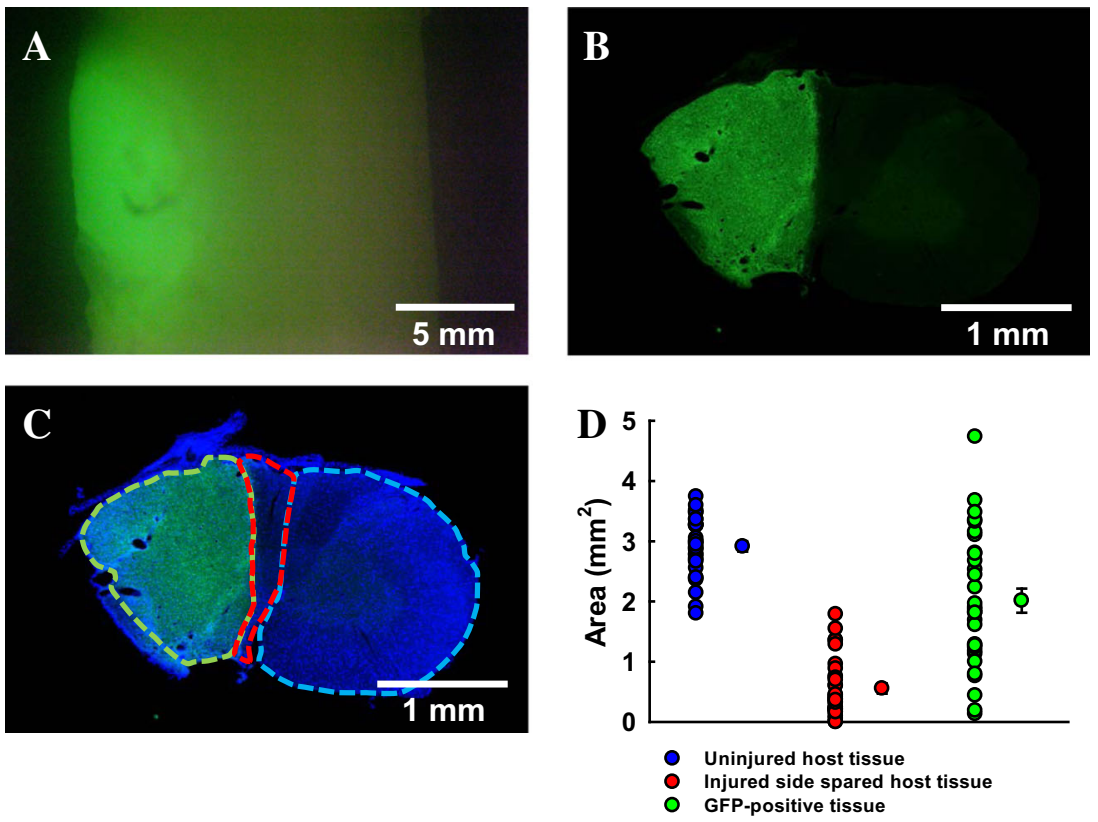

Fig. 3 Green fluorescence view of the (A) gross anatomy and (B) transverse spinal cord section from a $\mathrm{C} 4 \mathrm{Hx}+$ green fluorescence protein (GFP)-fetal spinal cord (FSC) animal. (C) Merged GFP (green) and 4',6diamidino-2-phenylindole (blue) image. The blue and red dashed lines in (C) label the areas of uninjured and injured side host spinal tissue, respectively.

The green dashed line in (C) labels the GFP-positive region indicating the putative FSC-derived graft location. (D) Individual and averaged value of the area of uninjured host tissue (blue), injured-side spared host tissue (red), and GFP-positive tissue (green) in C4Hx + GFP-FSC animals

Fig. 4 Horizontal section of cervical spinal cord from a $\mathrm{C} 4 \mathrm{Hx}+$ green fluorescence protein (GFP)-fetal spinal cord (FSC) animal. (A-C) Merged view of 4',6-diamidino-2phenylindole (blue), GFP (green), and cholera toxin subunit $\mathrm{B}$ (CT$\mathrm{B}$; red) images at the (A) dorsal, (B) central, and (C) ventral horizontal levels of the spinal cord. (D) Higher magnification image of the white box indicated in (C). (E) Enlarged view of the region labeled by the white box indicated in (D). Schematic diagrams of the transverse sections in $(\mathrm{A}-\mathrm{C})$ indicate the approximate horizontal level at which the images were photographed. The arrows in (C) indicate the CT-B-labeled phrenic motoneurons (red). The arrows in (E) indicate CT-B particles in the graft region. Scale bars $=1 \mathrm{~mm}$ in (A-C); $200 \mu \mathrm{m}$ in (D); and $50 \mu \mathrm{m}$ in $(\mathrm{E})$
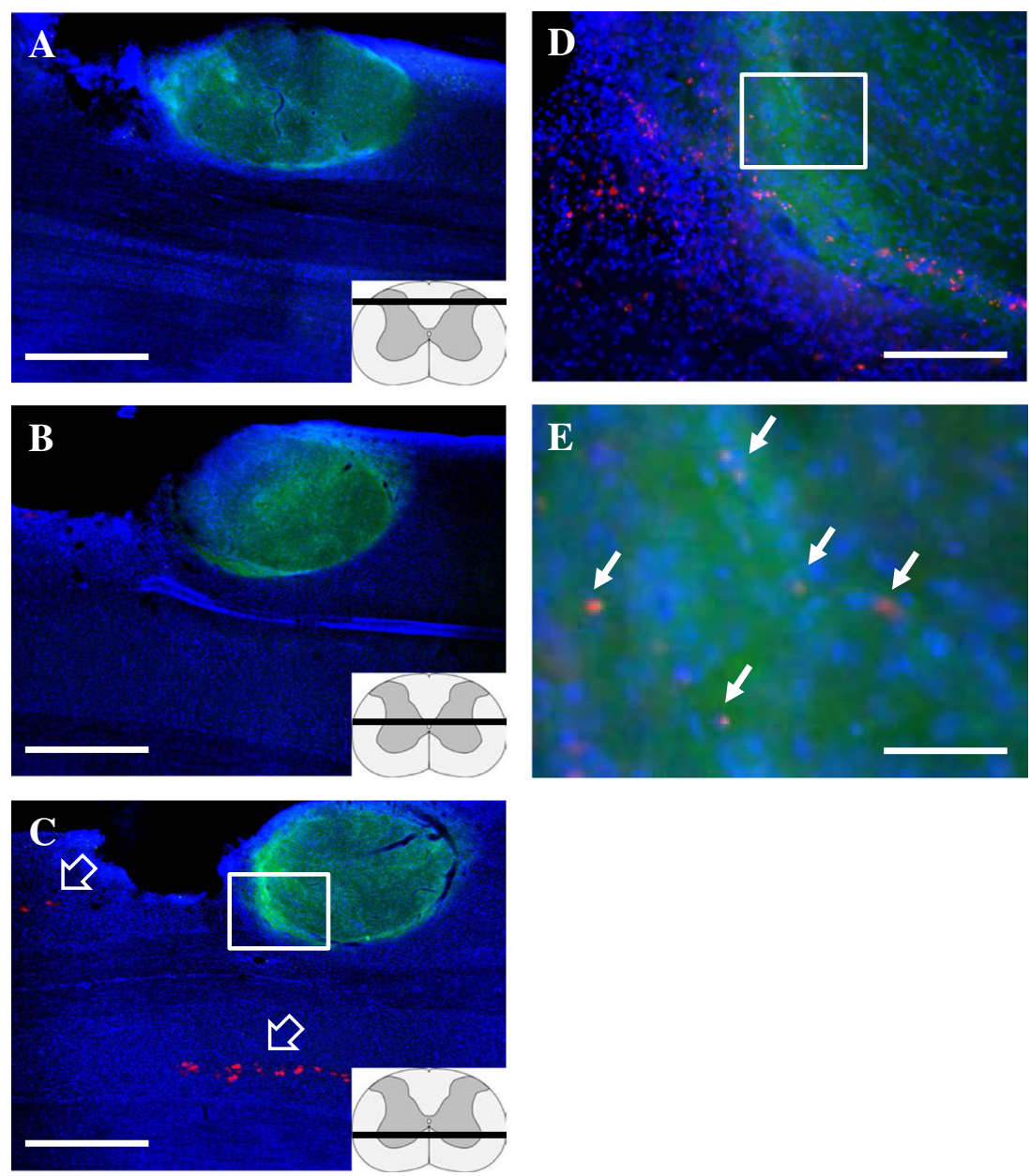
Fig. 5 Horizontal section of cervical spinal cord from a $\mathrm{C} 4 \mathrm{Hx}+$ green fluorescence protein (GFP)-fetal spinal cord (FSC) animal. (A-C) Merged view of 4',6-diamidino-2phenylindole (blue), GFP (green), and wheat germ agglutination (WGA; red) images at the (A) dorsal, (B) central, and (C) ventral horizontal levels of the spinal cord. (D) Higher magnification image of the white box indicated in (C). (E) Enlarged view of the region labeled by the white box indicated in (D). Schematic diagrams of the transverse sections in $(\mathrm{A}-\mathrm{C})$ indicate the approximate horizontal level at which the images were photographed. The arrows in (C) indicate the WGA-labeled phrenic motoneurons (red). The arrows in (E) point out the WGAlabeled cells in the graft region. Scale bars $=1 \mathrm{~mm}$ in $(\mathrm{A}-\mathrm{C})$; $200 \mu \mathrm{m}$ in (D); $50 \mu \mathrm{m}$ in (E)
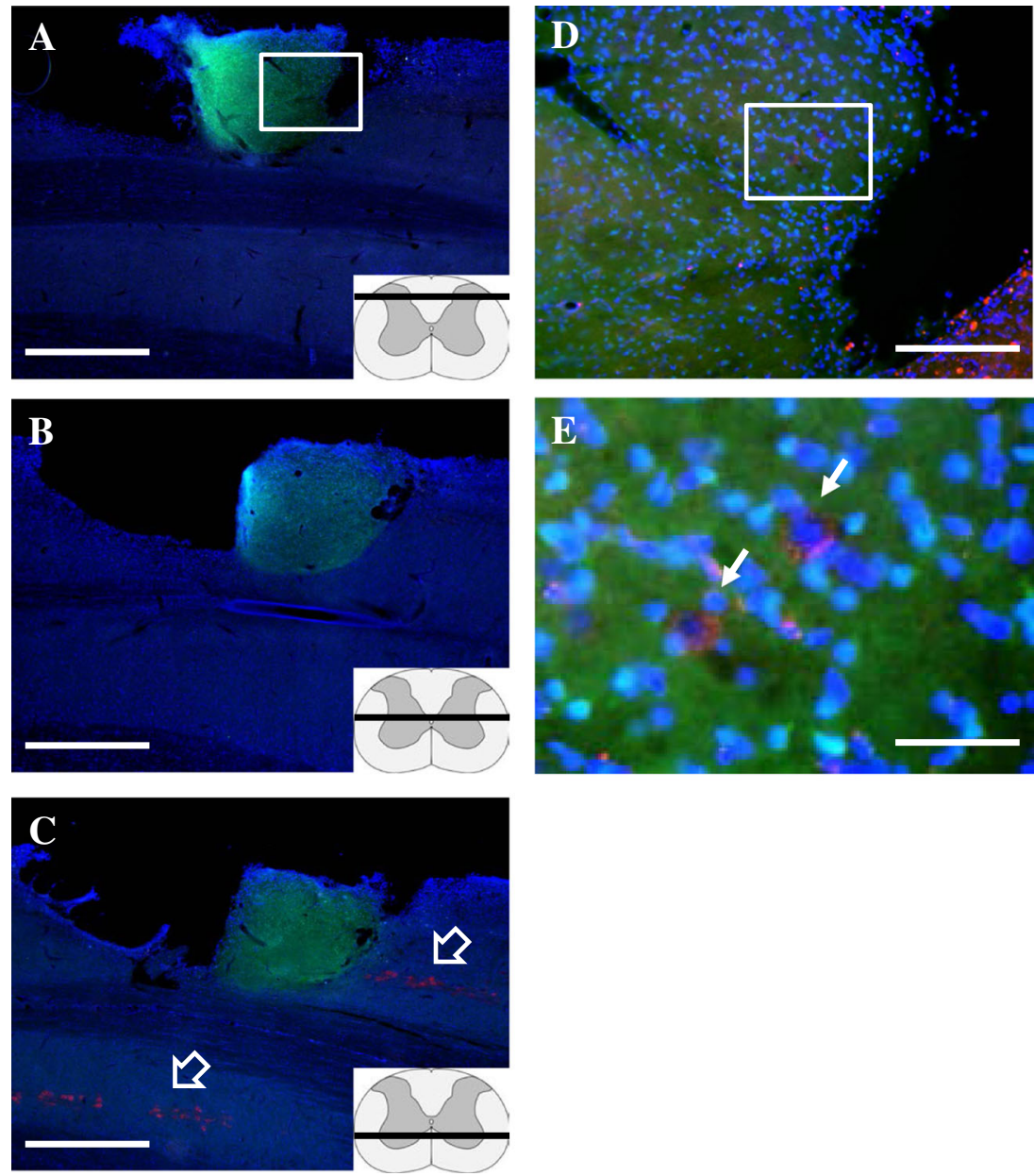

sections demonstrated that some NeuN- (Fig. 6A), GFAP(Fig. 6B), and Iba1-positive (Fig. 6C) cells were co-localized with GFP-positive tissue, suggesting that the GFP-FSC grafts were composed of these neural cells. FSC-derived NeuN cells were scattered within the graft region without specific distribution (Fig. 6A). This pattern was different from the uninjured side host tissue, where NeuN-positive cells were mainly located in the gray matter. We further compare the area fraction of individual neural markers between the graft tissue and host gray and white matter tissue. Specifically, the area fraction of NeuN expression within the graft is $6.5 \pm 2.1 \%$, which was significantly greater than that of the host white matter $(2.0 \pm 0.4 \%)$ but lower than the expression in the host gray matter $[11.3 \pm 1.5 \% ; p<0.05$ (Fig. 7A)]. The area fraction of GFAP expression was greater in the graft $(19.5 \pm 6.3 \%)$ than in the host gray matter $[1.1 \pm 0.3 \% ; p<0.05$ (Fig. 7B)]. Moreover, the expression of Iba1 was substantially greater in the graft $(45.3 \pm 6.7 \%)$ than host tissue $(p<0.01 ;$ Fig. $7 C)$. In contrast to the robust expression of Iba1, the expression of RIP within the graft region $(4.5 \pm 4.1 \%)$ was significantly lower than that within the host white matter $[83.1 \pm 2.9 \% ; p<0.01$ (Fig. 7D)]. We also noted that the expression levels of Iba1 and RIP were different between graft and uninjured host tissue. Specifically, Iba1-positive cells were highly expressed within the graft region (Fig. 6C), suggesting that transplantation may trigger a series of immune responses in the graft. In addition, RIP signals were absent or very low in the graft than in the white matter of the uninjured side tissue (Fig. 6D).

To investigate whether host neural cells may migrate into the transplanted area, 4 neural markers (e.g., NeuN, GFAP, Ibal, and RIP) were examined in transverse spinal cord sections of GFP-C4Hx animals received nFSC tissue. Figure $8 \mathrm{~A}$ demonstrated that the whole spinal cord expressed GFP in GFP-C4Hx animals, and the spinal cord section also exhibited robust GFP expression in the uninjured side (e.g., right; Fig. 8B, C). Although GFP expression level was substantially lower in the transplanted area, we can still observe some GFP-positive cells in the graft area (Fig. 8C). The immunostaining of NeuN (Fig. 9A) and GFAP (Fig. 9B) demonstrated that the GFP-positive cells were not co-localized with NeuN- or GFAP-positive marker. However, Iba1-positive signals were highly overlapped with GFP-positive signals (Fig. 9C). These data suggested that both neuron and astrocyte in the transplanted area were mainly derived from transplanted FSC tissue, and host microglia can invade into the graft region. 
Fig. 6 The differentiation of green fluorescence protein (GFP)-fetal spinal cord (FSC)derived grafts. (a) Transverse spinal cord section stained with specific markers for neurons [(A) $\mathrm{NeuN}$, astrocytes [(B) glial fibrillary acidic protein (GFAP)], microglia $[(\mathrm{C})$ ionized calciumbinding adapter molecule 1 (Iba 1)], and oligodendrocytes [(D) receptor interacting protein (RIP)]. (b) Green fluorescence image indicating the graft region. (c) Higher magnification view of the merged image of the white boxes in (a) and (b)
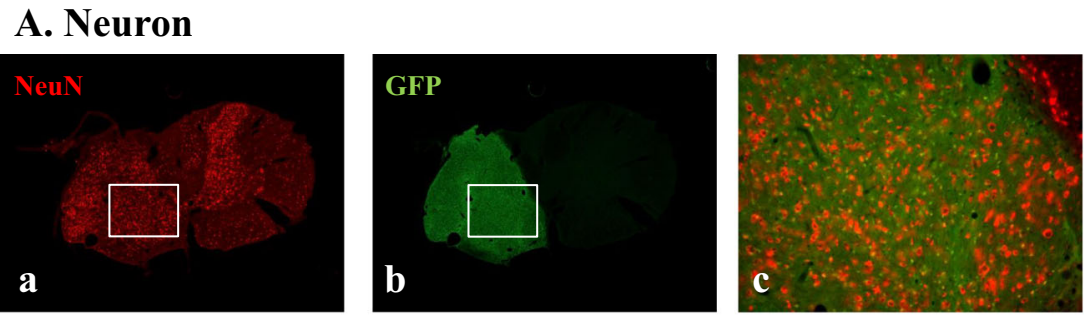

B. Astrocyte
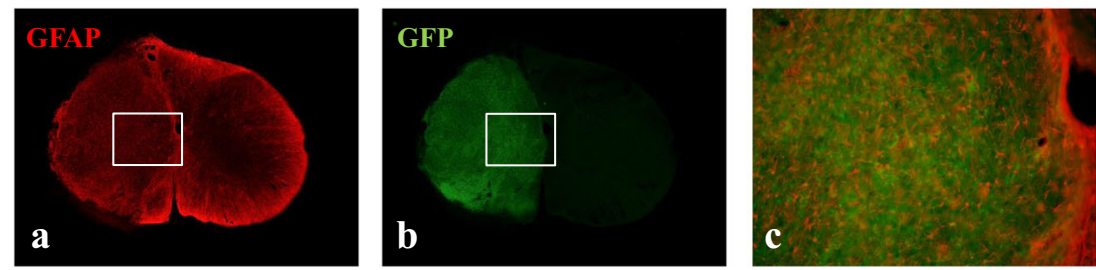

C. Microglia
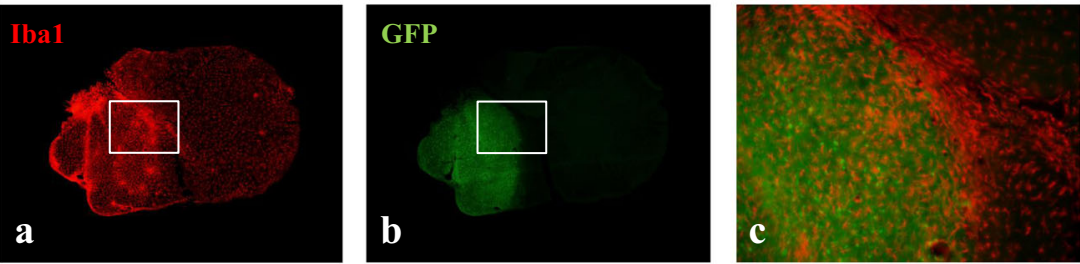

D. Oligodendrocyte
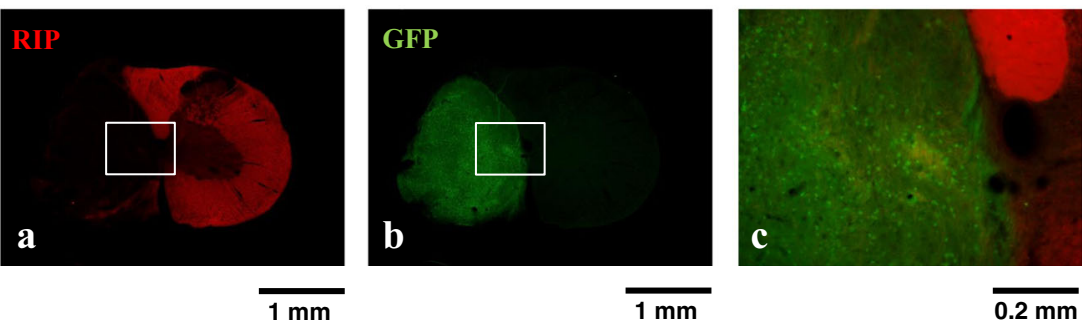

Our data also demonstrated the presence of a few 5hydroxytryptamine- (5-HT; Fig. 10A), ChAT- (Fig. 10B), and DBH-positive (Fig. 10C) cells within the graft regions in $\mathrm{C} 4 \mathrm{Hx}+\mathrm{GFP}-\mathrm{FSC}$ animals. Although these cells were not evenly distributed within the graft, the data indicate that neuron cells derived from the FSC may have the capacity to release 5HT, acetylcholine, or norepinephrine to modulate graft and/or host neuronal activity. In addition, robust expression of GAD(Fig. 11B) and VGLUT2-positive (Fig. 11C) fibers was detected throughout the graft region in $\mathrm{C} 4 \mathrm{Hx}+\mathrm{GFP}-\mathrm{FSC}$ animals. Interestingly, the expression of 5-HT fibers (Fig. 11A) was relatively higher in the grafts without 5-HT neurons than in those containing 5-HT-positive neurons (Fig. 10A).

\section{Connectivity Between the Graft and the Phrenic Motor System}

Connectivity between the graft and the phrenic motor system was evaluated using monosynaptic ( $n=4$, CT-B; Fig. 4) or trans-synaptic ( $n=7$, WGA; Fig. 5) retrograde tracers. Both tracers robustly labeled the phrenic motoneuron at the ventral layer of the spinal cord (Figs 4C and 5C). A few monosynaptic retrograde tracer particles accumulated around the hostgraft interface and within the graft (Fig. 4D, E). However, this type of labeling was relatively smaller than the general neuron labeling and did not reveal neuronal morphology as previous studies demonstrated [28, 29]; thus, we concluded that there were no CT-B-labeled neurons within the graft region and there was no direct connection between the graft and the diaphragm. The trans-synaptic retrograde tracer was detected around the graft region; however, we noticed the presence of a few tracer-labeled cells within the graft region in 6 of 7 animals that received WGA application (Fig. 5D, E), suggesting that the FSC-derived graft may be able to influence the host phrenic motor system through polysynaptic transmission.

\section{Impact of FSC Grafts on Respiratory Motor Outputs}

$\mathrm{C} 4 \mathrm{Hx}$ caused a deficiency in respiration, as reflected by lower tidal volume in both $\mathrm{C} 4 \mathrm{Hx}+\mathrm{FSC}$ and $\mathrm{C} 4 \mathrm{Hx}+\mathrm{HBSS}$ groups 
Fig. 7 The area fraction of immunofluorescence expression of neural markers [(A) NeuN; (B) glial fibrillary acidic protein (GFAP); (C) ionized calciumbinding adapter molecule 1 (Iba1); (D) receptor interacting protein (RIP)] within the graft region and host gray and white matter tissue. $* * p<0.01$ significant different expression between the host gray and white matter. $\theta p<0.05 . \theta \theta p<0.01$ compared with the value of the host gray matter. ${ }^{*} p<0.05$.

${ }^{\# \#} p<0.01$ compared with value of the host white matter

\section{A. NeuN}

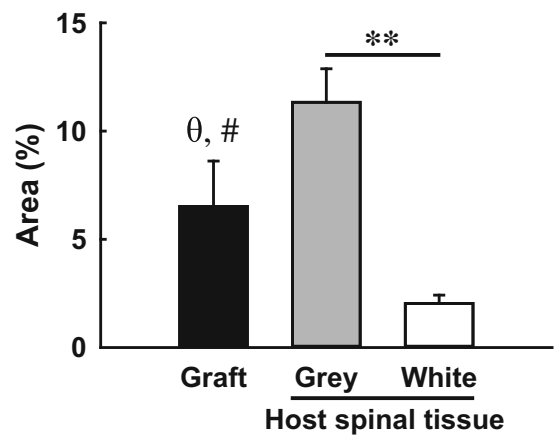

C. Iba1

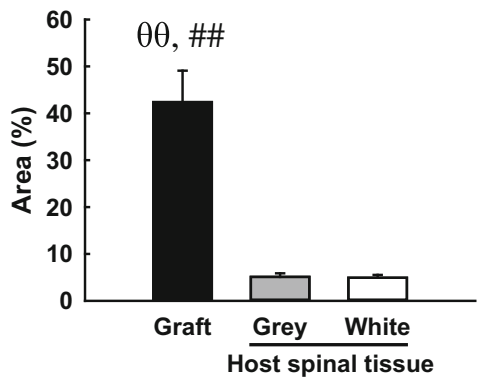

B. GFAP

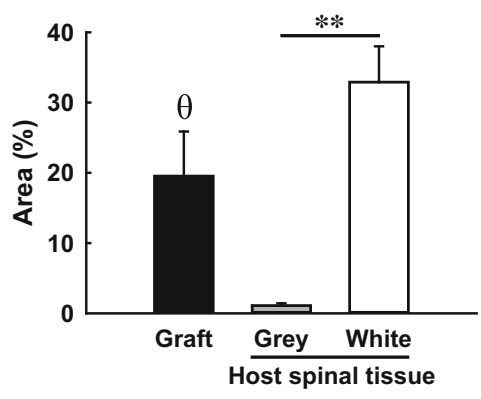

D. RIP

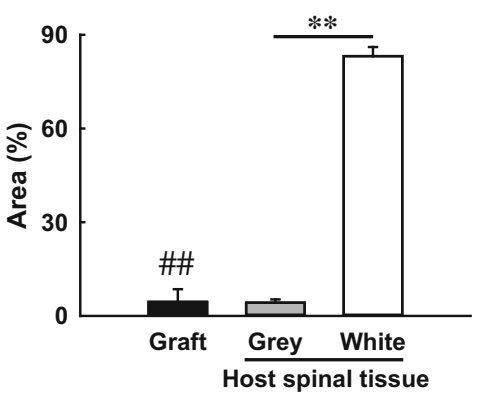

compared with uninjured animals at all time points (Table 1). The respiratory behavior of C4Hx + FSC and C4Hx + HBSS groups was similar before transplantation and did not show significant differences during baseline or hypoxia at 1 to 8 weeks post-transplantation. In addition, a series of linear regression analysis demonstrated that respiratory tidal volume was not dependent on the size of the spared host tissue (Fig. 12A, C) or the FSC graft (Fig. 12B, D) during the baseline and hypoxic breathing before and 8 weeks after transplantation (Fig. 12). These data indicated that the range of the injury severity performed in the present study did not significantly modulate the respiratory tidal volume and FSC transplantation did not significantly affect the overall respiratory behavior of unanesthetized animals.

To investigate specifically whether transplantation of FSC is able to influence phrenic motor output, bilateral phrenic nerve activity was recorded under different levels of respiratory drive (Fig. 13). During the baseline
Fig. 8 The green fluorescence view of the (A) gross spinal cord anatomy and (B-D) transverse spinal cord section from a green fluorescence protein- $\mathrm{C} 4 \mathrm{Hx}+$ normal fetal spinal cord animal. (A) Ventral view of the cervical spinal cord. (C, D) Higher magnification view of (B) labeled by solid and dash line, respectively
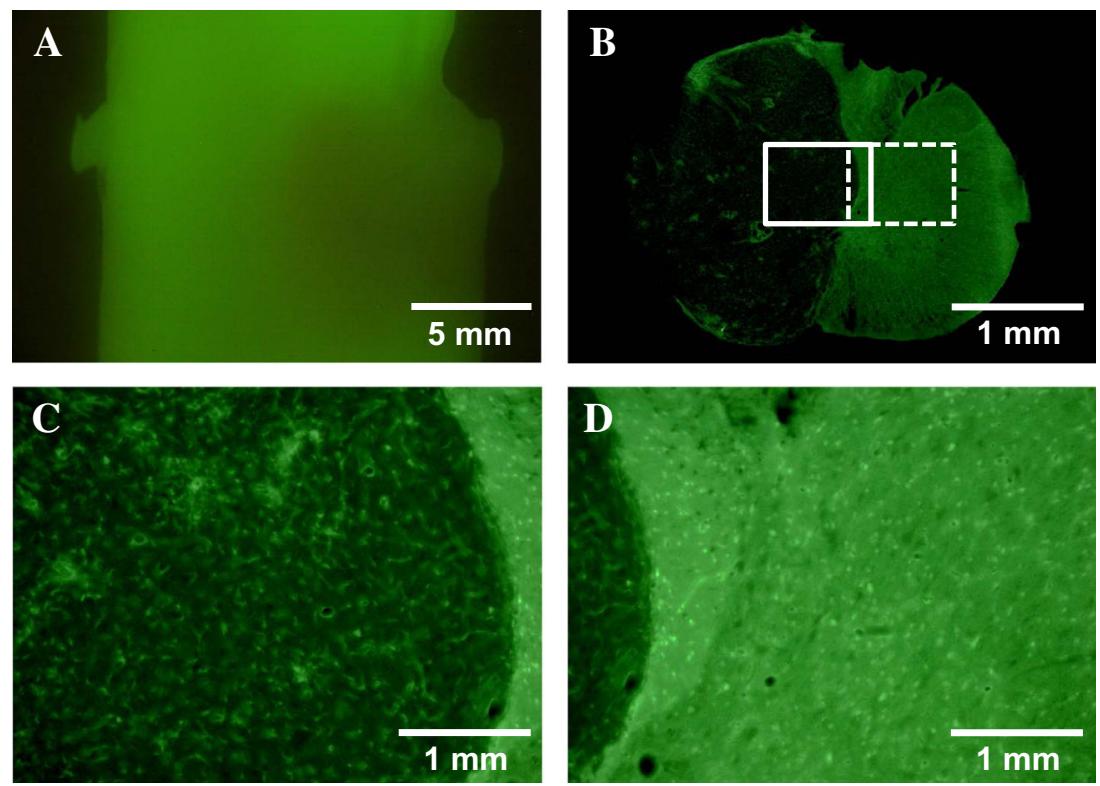
Fig. 9 The differentiation of fetal spinal cord-derived grafts in green fluorescence protein (GFP)C4Hx animals. (a) Transverse spinal cord section stained with specific markers for neurons [(A) $\mathrm{NeuN}$, astrocytes [(B) glial fibrillary acidic protein], microglia [(C) ionized calcium binding adapter molecule 1 (Iba 1)], and oligodendrocytes [(D) receptor interacting protein (RIP)]. (b) Green fluorescence image indicating the host tissue. (c) Higher magnification view of the merged image of the white boxes in (a) and (b)
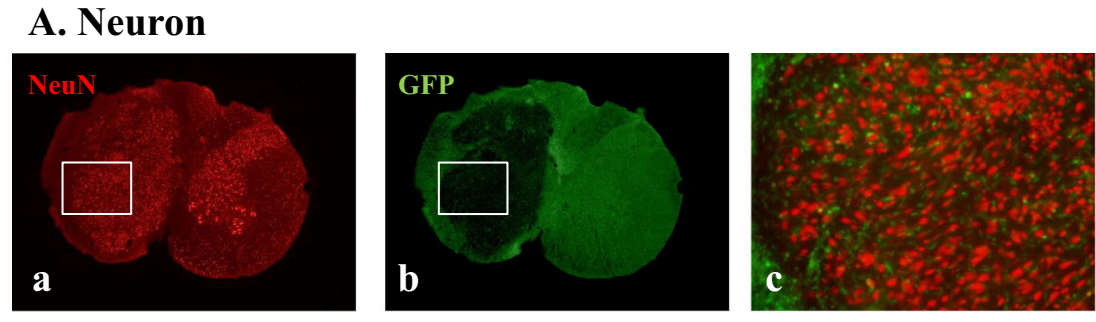

B. Astrocyte
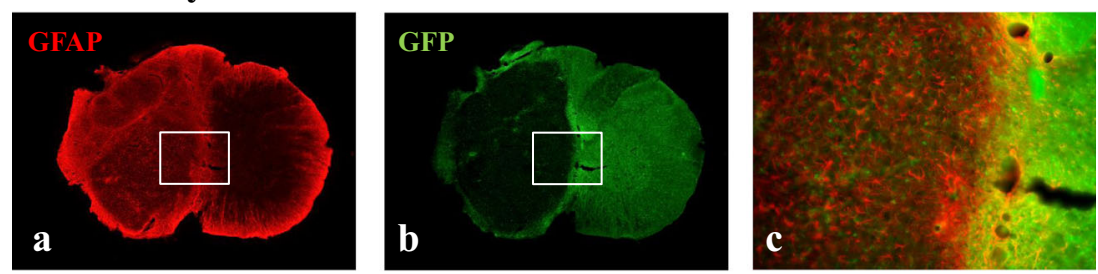

C. Microglia
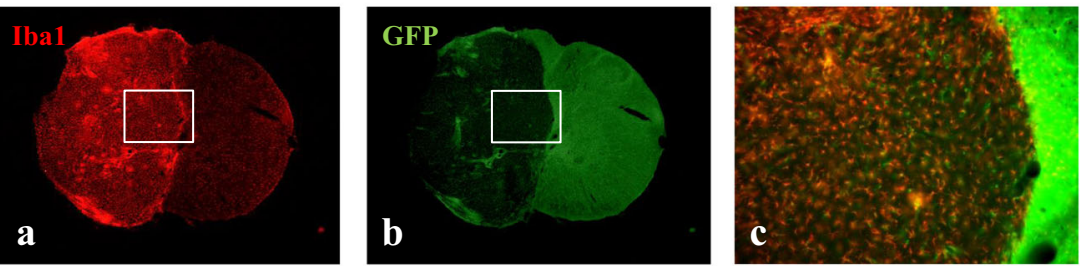

D. Oligodendrocyte
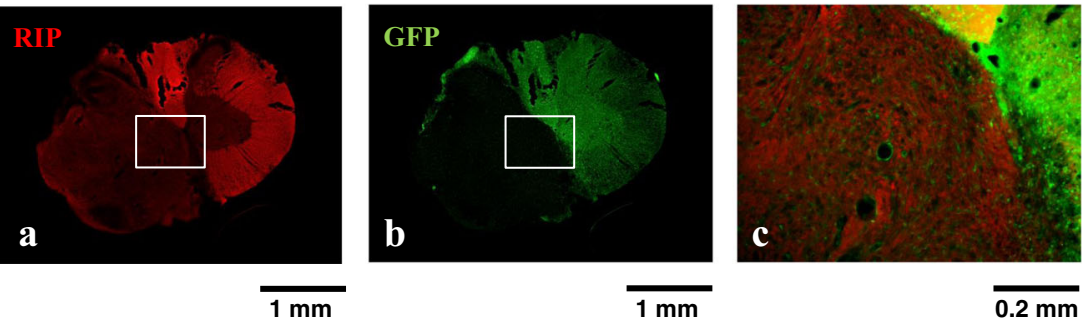

condition, both phrenic nerves exhibited inspiratory rhythmic bursting, with similar contralateral phrenic burst amplitude and frequency across groups (Table 2). However, the ipsilateral phrenic burst amplitude observed in C4Hx + HBSS animals $(50.3 \pm 7.6 \%$ max $)$ was significantly greater than that of uninjured animals $(34.2 \pm 2.4 \%$ $\max )$ and $\mathrm{C} 4 \mathrm{Hx}+\mathrm{nFSC}$ animals $(35.1 \pm 2.9 \% \max )$ when the data were normalized by a maximum value (\% max) $(p<0.05$; Fig. 14F). Phrenic burst amplitude increased with increasing respiratory drives, as expected; however, several different patterns were seen between $\mathrm{C} 4 \mathrm{Hx}+$ nFSC and C4HX + HBSS groups. First, the asphyxic response of the contralateral phrenic nerve in $\mathrm{C} 4 \mathrm{Hx}+\mathrm{nFSC}$ $(307 \pm 40 \%$ BL) animals was significantly greater than the response in $\mathrm{C} 4 \mathrm{Hx}+\mathrm{HBSS}$ animals $[243 \pm 28 \% \mathrm{BL}$; $p<0.05$ (Fig. 14C)]. Second, the absolute value of the ipsilateral phrenic burst amplitude of $\mathrm{C} 4 \mathrm{Hx}+\mathrm{nFSC}$ animals $(0.34 \pm 0.06 \mathrm{mV})$ was significantly greater than $\mathrm{C} 4 \mathrm{Hx}+\mathrm{HBSS}$ animals $(0.22 \pm 0.04 \mathrm{mV})$, and was comparable to uninjured animals $(0.39 \pm 0.04 \mathrm{mV})$ (Fig. 14B).

\section{Discussion}

The present study demonstrated that FSC grafts survived in hemisected cervical spinal cord for at least 8 weeks posttransplantation and were able to differentiate into neurons and astrocytes, and express specific neurochemical markers (e.g., 5-HT, ChAT, or DBH). The grafts were innervated by endogenous or exogenous serotonergic, noradrenergic, cholinergic, glutamatergic, or $\gamma$-aminobutyric acid-ergic fibers. The retrograde tracer revealed a minor integration between grafts and the host phrenic system through polysynaptic connections, a linkage that may modulate phrenic bursting under high respiratory drives.

\section{Lesion Severity}

The present study observed that there was a minor spared host tissue ipsilateral to the lesion, suggesting animals received an incomplete hemisection at the cervical spinal cord. The histological data demonstrated that the injured side spared host 
Fig. 10 Neurochemical phenotype of green fluorescence protein (GFP)-fetal spinal cord graft neurons. (a) Transverse spinal cord section

immunostained with the neurochemical markers for serotonergic [(A) 5-

hydroxytryptamine (5-HT)], cholinergic $[(\mathrm{B})$ choline acetyltransferase (ChAT)], and noradrenergic $[(\mathrm{C})$ dopamine beta hydroxylase (DBH)] cells. (b) Green fluorescence image indicating the graft region. (C) Higher magnification view of the merged image from the white boxes indicated in (a) and (b)
A. Serotonergic cell
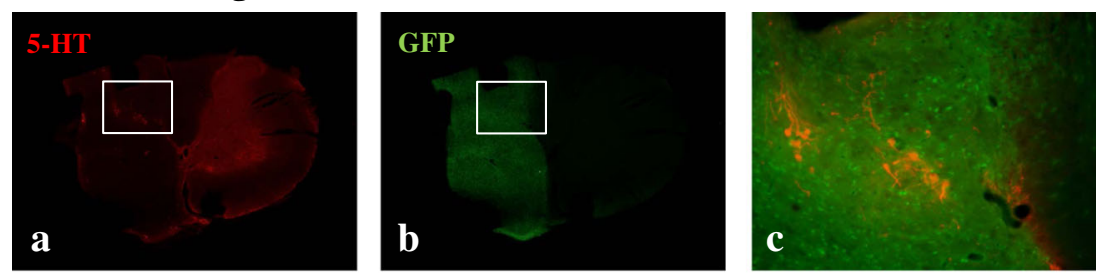

B. Cholinergic cell
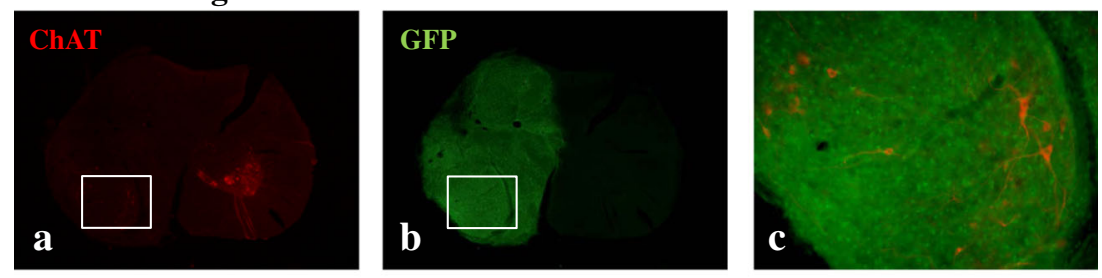

C. Noradrenergic cell
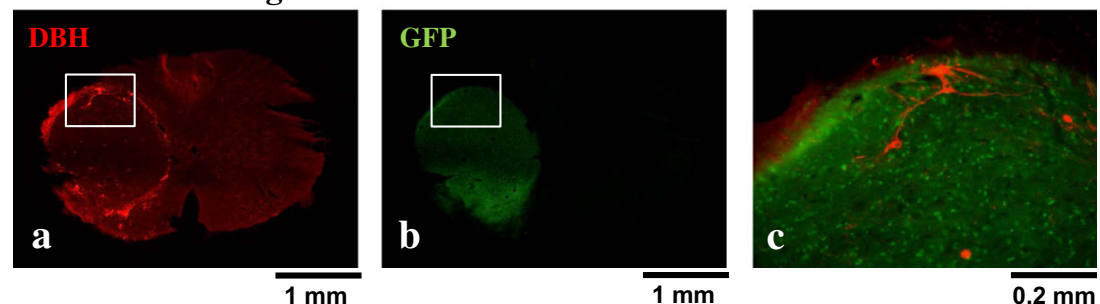

tissue was $19.0 \pm 3.1 \%$ of the contralateral uninjured side host spinal tissue in $\mathrm{C} 4 \mathrm{Hx}+\mathrm{FSC}$ animals. In other words, the lesion cavity was $\sim 80 \%$ of the normal spinal tissue, which should be considered as a severe injury. A series of linear regression analyses also implied that neither injury severity nor the size of FSC graft significantly modulated the
Fig. 11 (A) Serotonergic, (B) $\gamma$ aminobutryic acid (GABA)-ergic, and $(\mathrm{C})$ glutamatergic innervation of green fluorescence protein (GFP)-fetal spinal cord graft. (a) Transverse spinal cord section immunostained with the neurochemical markers for serotonergic [(A) 5hydroxytryptamine (5-HT)], GABAergic [(B) decarboxylase (GAD)], and glutamatergic [(C) vesicular glutamate transporter 2 (VGLUT2)] fibers. (b) Green fluorescence image indicating the graft region. (C) Higher magnification view of the merged image from the white boxes indicated in (a) and (b)

\section{A. Serotonergic fiber}
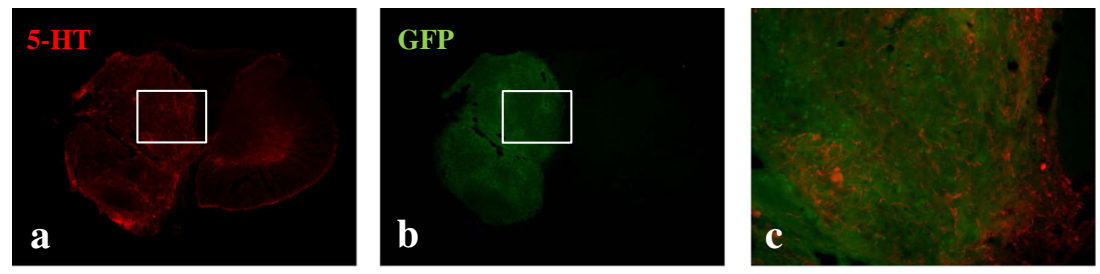

B. GABAergic fiber
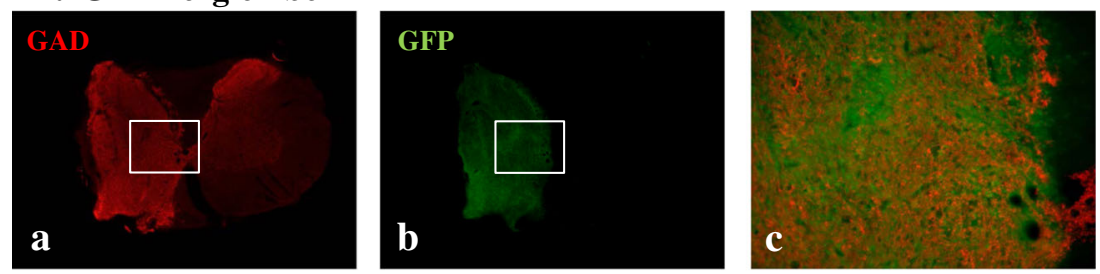

C. Glutamatergic fiber
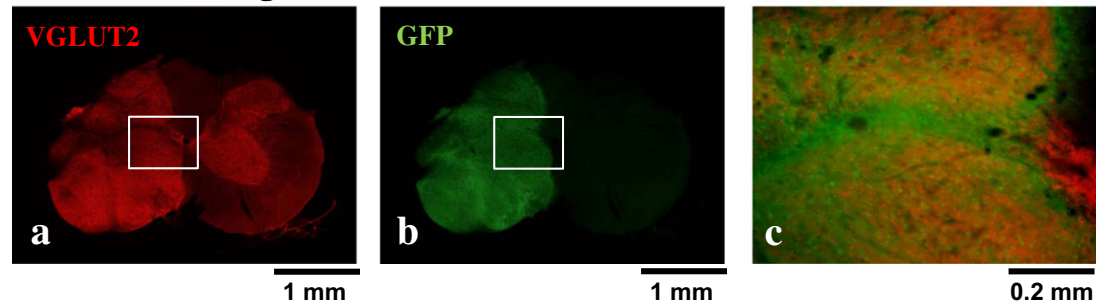
Table 1 The body weight and respiratory behavior of unanesthetized rats before and after transplantation

\begin{tabular}{|c|c|c|c|c|c|}
\hline \multirow[t]{2}{*}{ Weight (g) } & \multicolumn{5}{|c|}{ Time post-transplantation } \\
\hline & Before & $1 \mathrm{wk}$ & $2 \mathrm{wk}$ & $4 \mathrm{wk}$ & $8 \mathrm{wk}$ \\
\hline Uninjured & $344 \pm 10$ & $363 \pm 9$ & $379 \pm 16^{*}$ & $463 \pm 9^{\dagger}$ & $550 \pm 14^{\ddagger}$ \\
\hline $\mathrm{C} 4 \mathrm{Hx}+\mathrm{HBSS}$ & $318 \pm 5$ & $337 \pm 7^{*}$ & $369 \pm 9^{\S}$ & $431 \pm 7^{\dagger}$ & $488 \pm 9^{ \pm, \pi}$ \\
\hline $\mathrm{C} 4 \mathrm{Hx}+\mathrm{FSC}$ & $340 \pm 5$ & $364 \pm 5^{*}$ & $397 \pm 5^{\S}$ & $450 \pm 6^{\dagger}$ & $510 \pm 7^{\ddagger, \mathbb{I}}$ \\
\hline \multicolumn{6}{|c|}{ Respiratory frequency (breaths/min) } \\
\hline \multirow[t]{2}{*}{ Baseline } & \multicolumn{5}{|c|}{ Time post-transplantation } \\
\hline & Before & $1 \mathrm{wk}$ & $2 \mathrm{wk}$ & $4 \mathrm{wk}$ & $8 \mathrm{wk}$ \\
\hline Uninjured & $99 \pm 2$ & $87 \pm 3$ & $83 \pm 4^{*}$ & $101 \pm 5^{\|}$ & $96 \pm 4$ \\
\hline $\mathrm{C} 4 \mathrm{Hx}+\mathrm{HBSS}$ & $122 \pm 7^{\text {I }}$ & $118 \pm 5^{q}$ & $111 \pm 6^{\mathrm{q}}$ & $122 \pm 7^{\text {q }}$ & $105 \pm 7^{*, * *}$ \\
\hline $\mathrm{C} 4 \mathrm{Hx}+\mathrm{FSC}$ & $111 \pm 2^{\dagger \dagger}$ & $110 \pm 2^{\mathrm{q}}$ & $112 \pm 3^{\text {TI }}$ & $110 \pm 3^{\dagger \dagger}$ & $102 \pm 2^{*}$ \\
\hline \multirow[t]{2}{*}{ Hypoxia } & \multicolumn{5}{|c|}{ Time post-transplantation } \\
\hline & Before & $1 \mathrm{wk}$ & $2 \mathrm{wk}$ & $4 \mathrm{wk}$ & $8 \mathrm{wk}$ \\
\hline Uninjured & $196 \pm 13$ & $180 \pm 11$ & $155 \pm 12^{\S}$ & $206 \pm 10^{\|,+*}$ & $191 \pm 9^{\|}$ \\
\hline $\mathrm{C} 4 \mathrm{Hx}+\mathrm{HBSS}$ & $194 \pm 5$ & $203 \pm 8$ & $203 \pm 6^{\mathbb{\pi}}$ & $198 \pm 5$ & $196 \pm 6$ \\
\hline $\mathrm{C} 4 \mathrm{Hx}+\mathrm{FSC}$ & $186 \pm 3$ & $195 \pm 3^{*}$ & $194 \pm 3^{\text {II }}$ & $194 \pm 3$ & $185 \pm 3^{* t}$ \\
\hline \multicolumn{6}{|l|}{ Tidal volume (ml) } \\
\hline \multirow[t]{2}{*}{ Baseline } & \multicolumn{5}{|c|}{ Time post-transplantation } \\
\hline & Before & $1 \mathrm{wk}$ & $2 \mathrm{wk}$ & $4 \mathrm{wk}$ & $8 \mathrm{wk}$ \\
\hline Uninjured & $1.59 \pm 0.08$ & $1.83 \pm 0.05^{*}$ & $1.86 \pm 0.10^{*}$ & $2.16 \pm 0.09^{\dagger}$ & $2.39 \pm 0.15^{\star}$ \\
\hline $\mathrm{C} 4 \mathrm{Hx}+\mathrm{HBSS}$ & $1.34 \pm 0.09$ & $1.39 \pm 0.07^{\mathbb{I}}$ & $1.55 \pm 0.06^{\S, \pi}$ & $1.71 \pm 0.09^{\dagger, \pi}$ & $1.88 \pm 0.11^{\ddagger, \pi}$ \\
\hline $\mathrm{C} 4 \mathrm{Hx}+\mathrm{FSC}$ & $1.37 \pm 0.03$ & $1.44 \pm 0.03^{*,,[}$ & $1.58 \pm 0.03^{\S, \pi}$ & $1.74 \pm 0.04^{\dagger, \mathbb{I}}$ & $1.94 \pm 0.04^{\ddagger, \pi}$ \\
\hline \multirow[t]{2}{*}{ Hypoxia } & \multicolumn{5}{|c|}{ Time post-transplantation } \\
\hline & Before & $1 \mathrm{wk}$ & $2 \mathrm{wk}$ & $4 \mathrm{wk}$ & $8 \mathrm{wk}$ \\
\hline Uninjured & $2.51 \pm 0.19$ & $2.90 \pm 0.16^{*}$ & $3.26 \pm 0.37^{\S}$ & $2.42 \pm 0.27^{\S}$ & $3.74 \pm 0.27^{\dagger}$ \\
\hline $\mathrm{C} 4 \mathrm{Hx}+\mathrm{HBSS}$ & $2.51 \pm 0.21$ & $2.38 \pm 0.15^{\mathscr{\Psi}}$ & $2.45 \pm 0.13^{\mathrm{TI}}$ & $2.75 \pm 0.16^{\mathrm{gl}}$ & $2.94 \pm 0.23^{\dagger, \pi}$ \\
\hline $\mathrm{C} 4 \mathrm{Hx}+\mathrm{FSC}$ & $2.14 \pm 0.06$ & $2.23 \pm 0.05^{\mathscr{\Psi}}$ & $2.39 \pm 0.06^{\S, \mathbb{I}}$ & $2.63 \pm 0.07^{\dagger, \text {,I }}$ & $2.89 \pm 0.07^{\ddagger, \mathbb{N}}$ \\
\hline \multicolumn{6}{|c|}{ Minute ventilation $(\mathrm{ml} / \mathrm{min})$} \\
\hline \multirow[t]{2}{*}{ Baseline } & \multicolumn{5}{|c|}{ Time post-transplantation } \\
\hline & Before & $1 \mathrm{wk}$ & $2 \mathrm{wk}$ & $4 \mathrm{wk}$ & $8 \mathrm{wk}$ \\
\hline Uninjured & $151 \pm 6$ & $153 \pm 6$ & $152 \pm 15$ & $210 \pm 13^{\dagger}$ & $222 \pm 18^{\dagger}$ \\
\hline $\mathrm{C} 4 \mathrm{Hx}+\mathrm{HBSS}$ & $156 \pm 9$ & $155 \pm 10$ & $161 \pm 7$ & $195 \pm 10^{\dagger}$ & $193 \pm 12^{\dagger}$ \\
\hline $\mathrm{C} 4 \mathrm{Hx}+\mathrm{FSC}$ & $147 \pm 2$ & $155 \pm 3$ & $172 \pm 5^{\S}$ & $187 \pm 5^{\dagger}$ & $191 \pm 5^{\dagger, \pi}$ \\
\hline \multirow[t]{2}{*}{ Hypoxia } & \multicolumn{5}{|c|}{ Time post-transplantation } \\
\hline & Before & $1 \mathrm{wk}$ & $2 \mathrm{wk}$ & $4 \mathrm{wk}$ & $8 \mathrm{wk}$ \\
\hline Uninjured & $471 \pm 39$ & $496 \pm 25$ & $502 \pm 85$ & $668 \pm 58^{\dagger}$ & $670 \pm 35^{\dagger}$ \\
\hline $\mathrm{C} 4 \mathrm{Hx}+\mathrm{HBSS}$ & $464 \pm 36$ & $441 \pm 28$ & $482 \pm 24$ & $544 \pm 28^{\dagger, \pi}$ & $571 \pm 40^{\dagger, \text { II }}$ \\
\hline $\mathrm{C} 4 \mathrm{Hx}+\mathrm{FSC}$ & $388 \pm 11$ & $421 \pm 9^{*}$ & $450 \pm 11^{\S}$ & $494 \pm 14^{\dagger, \text { I }}$ & $520 \pm 15^{\dagger,, \mathrm{I}}$ \\
\hline
\end{tabular}

Data are mean \pm SEM

${ }^{*} p<0.05$ compared with the value before transplantation

${ }^{\dagger} p<0.05$ compared with the value before and at 1 and 2 weeks post-transplantation

${ }^{\star} p<0.05$ compared with the value before, and at 1,2 , and 4 weeks post-transplantation

${ }^{\S} p<0.05$ compared with the value before and at $1 \mathrm{wk}$ post-transplantation

II $p<0.05$ vs uninjured group

${ }^{\|} p<0.05$ compared with the value at 2 weeks post-transplantation

${ }^{* *} p<0.05$ compared with the value at 4 weeks post-transplantation

${ }^{\dagger \dagger} p<0.05$ vs $\mathrm{C} 4 \mathrm{Hx}+\mathrm{HBSS}$ group

\$t $p<0.05$ compared with the value at 1 week post-transplantation

HBSS $=$ Hank's balanced buffer solution; FSC $=$ fetal spinal cord respiratory tidal volume recovery in unanesthetized rats. These data suggested that the incomplete hemilesion in the present study may not have a substantial impact on the respiratory function.

\section{Survival of FSC Grafts}

FSC tissue has been used as a cellular resource for spinal cord repair [30, 31]. Our results demonstrated that FSC-derived 
Fig. 12 Linear regression analysis of $(\mathrm{A}, \mathrm{C})$ tidal volume and size of spared host tissue and $(\mathrm{B}, \mathrm{D})$ green fluorescence protein (GFP)-positive tissue (i.e., the putative fetal spinal cord-derived graft) before and at 8 weeks posttransplantation during the baseline and hypoxia

Baseline

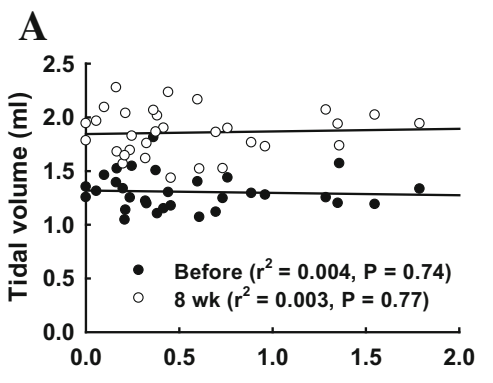

Injured side spared host tissue $\left(\mathrm{mm}^{2}\right)$

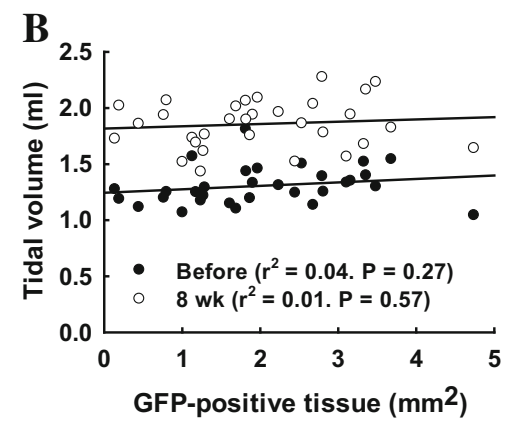

\section{Hypoxia}

C

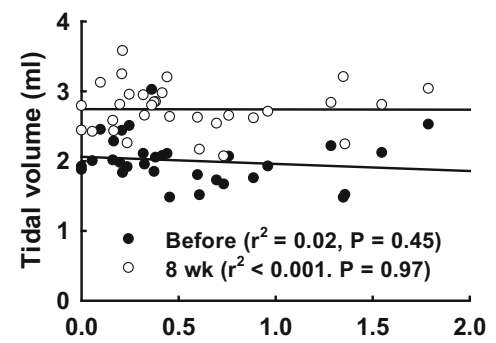

Injured side spared host tissue $\left(\mathrm{mm}^{2}\right)$
D

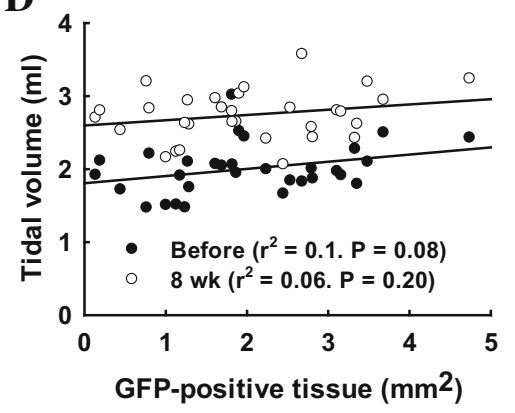

Baseline Vagotomy Hypoxia Asphyxia

\section{Uninjured}

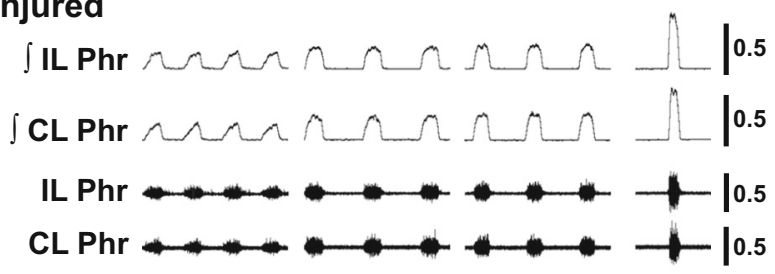

\section{C4Hx + HBSS}

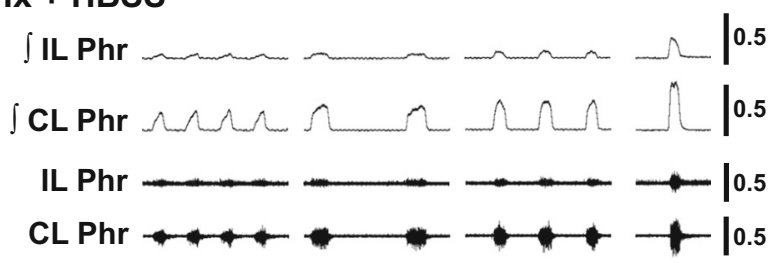

\section{$\mathrm{C} 4 \mathrm{Hx}+\mathrm{nFSC}$}

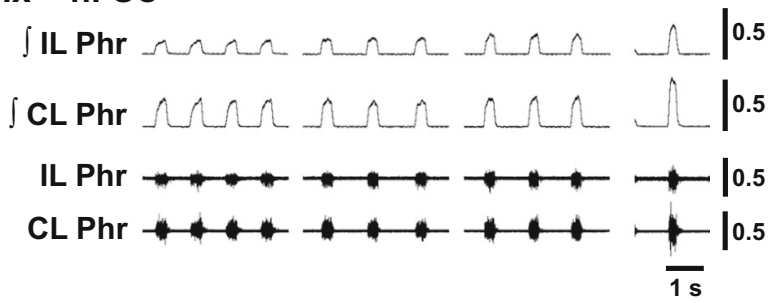

Fig. 13 Representative examples of bilateral phrenic neurograms recorded in an uninjured, C4Hx + Hank's balanced saline solution (HBSS) and $\mathrm{C} 4 \mathrm{Hx}+$ normal fetal spinal cord (nFSC) rat under different levels of respiratory drive. The unit of the burst amplitude is $\mathrm{mV}$. $\mathrm{CL}=$ contralateral; $\mathrm{IL}=$ ipsilateral; $\mathrm{Phr}=$ phrenic. $\int=$ smoothed and rectified signals grafts can fill the lesion cavity and survive in the injured spinal cord for at least 8 weeks. However, the FSC-derived tissue did not completely contact or integrate with the host tissue. Because the hemisection was created by incision and aspiration using a micropipette, which caused a significant lesion cavity. Moreover, the fetal spinal cord tissue but not cell suspension was transplanted into the cavity. Therefore, it is unlikely that the dissected piece of the fetal spinal cord tissue can completely fill the lesion cavity. Additionally, previous studies have shown that there is an initial cell attrition in FSC graft following acute transplantation into the injured cord [21,24]. Our current data also demonstrated that there was a robust expression of microglia within the graft. Accordingly, attrition of the graft tissue and/or infiltration of microglia/macrophage may reduce the host-graft integration. However, even although the graft tissue did not fully and completely contact

Table 2 Respiratory frequency (breaths/min) of anesthetized and ventilated animals

\begin{tabular}{llll}
\hline & Baseline & Vagotomy & Hypoxia \\
\hline Uninjured & $64 \pm 1$ & $42 \pm 3^{*}$ & $51 \pm 2^{\dagger}$ \\
C4Hx + HBSS & $64 \pm 1$ & $45 \pm 3^{*}$ & $56 \pm 2^{\dagger}$ \\
C4Hx + nFSC & $64 \pm 1$ & $49 \pm 4^{*}$ & $59 \pm 2^{\dagger}$ \\
\hline
\end{tabular}

Data are mean \pm SEM

${ }^{*} p<0.01$ compared with value during the baseline

${ }^{\dagger} p<0.01$ compared with the value after vagotomy

HBSS $=$ Hank's balanced buffer solution; $\mathrm{nFSC}=$ normal fetal spinal cord 
Fig. 14 Bilateral phrenic burst amplitude recorded in uninjured, C4Hx + Hank's balanced saline solution (HBSS) and C4Hx + normal fetal spinal cord (nFSC) rats. Data are expressed in (A, B) arbitrary units $(\mathrm{mV}),(\mathrm{C}, \mathrm{D})$ percentage of the baseline (\% $\mathrm{BL})$, and (E, F) percentage of the maximum value during asphyxia (\% max). * $p<0.05$. ** $p<0.01$ significant differences from control animals. ${ }^{\#} p<0.05$. ${ }^{\# \#} p<0.01$ significant differences between $\mathrm{C} 4 \mathrm{Hx}+\mathrm{HBSS}$ and $\mathrm{C} 4 \mathrm{Hx}+\mathrm{nFSC}$ animals. ${ }^{\mathrm{a}} p<0.05$ compared with the value during the baseline condition. ${ }^{\mathrm{b}} p<0.05$ compared with the value during the baseline and vagotomized conditions. ${ }^{\mathrm{c}} p<0.05$ compared with the value during the baseline, vagotomized, and hypoxic conditions
A

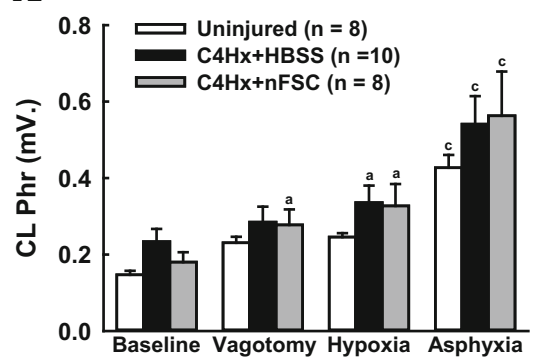

C

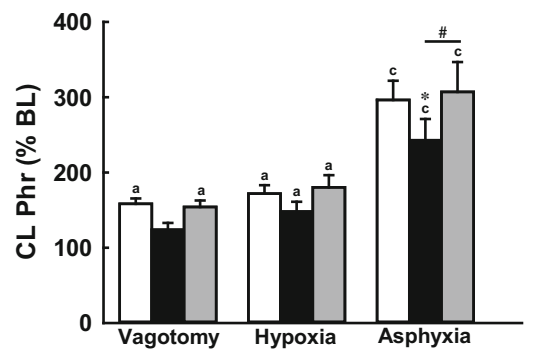

E

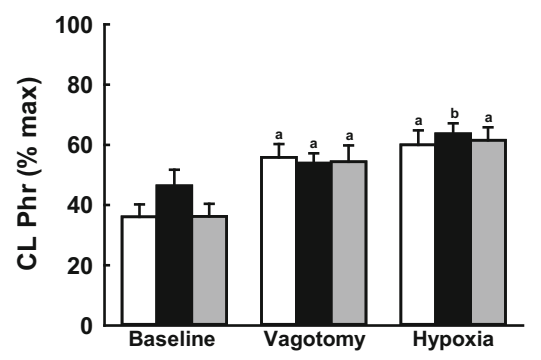

B

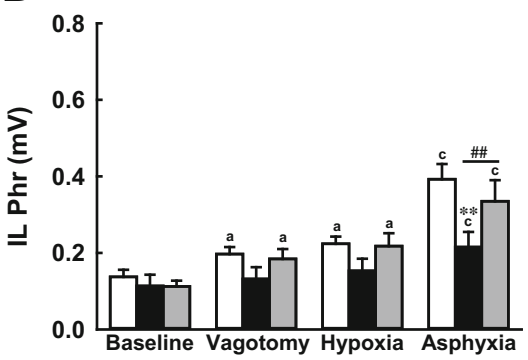

D

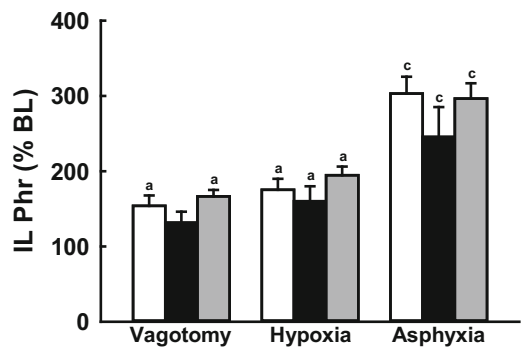

F

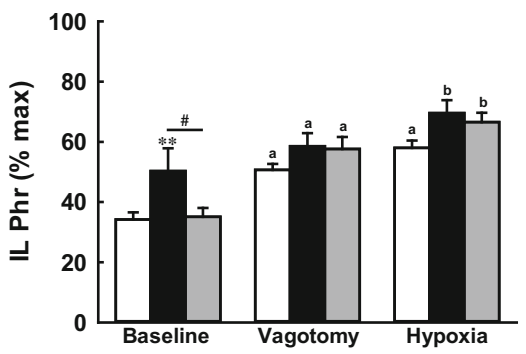

with the host tissue, our data showed that the area of the graft can reach $75 \pm 9 \%$ of the contralateral host spinal tissue, indicating that the graft has the capability of filling the lesion cavity without specific interventions.

The day-14 embryonic FSC is mainly composed of neuronal/glial restricted precursors, a few neural stem cells and differentiated neural cells, as well as non-neural cells and cellular matrix [21, 22]. Lepore and Fischer [21] demonstrated that neuronal and glial restricted precursors transplanted into injured spinal cord can survive and fill the lesion without early cell loss [21]. Therefore, we suspected that the capacity of FSC to fill SC lesions was primarily due to the proliferation and differentiation of residual neural precursors within FSC tissue. Here, FSC was transplanted into the lesion cord at 1 week postinjury, and Coumans et al. [32] proposed that microenvironment of injured cord at the subchronic or chronic stage is favorable for cell growth compared with the acute injury phase. Accordingly, we cannot exclude that the lesion may be partially filled by the original differentiated neural cells within FSC.

\section{Differentiation of FSC Grafts}

Our data showed the presence of NeuN- and GFAP-positive cells within the graft, suggesting FSC tissue may have the capacity to differentiate into neurons and astrocytes. Although many microglia were observed in the graft, the immunostaining of spinal cord sections of GFP-C4Hx + nFSC animals indicated that occurrence of these microglia were primarily due to migration of host cells. The proportion of oligodendrocytes was very low in the grafts, as reflected by the low expression of RIP signals. A similar differentiated pattern of FSC tissue has been reported in previous studies. Jakeman et al. [33], for example, found that FSC tissue was composed of numerous tightly packed neurons with a less myelinated region at 1 to 4 months after acute transplantation into injured cord. White et al. [20] also found that FSC-derived grafts were generally similar to the spinal gray matter. Lepore and Fischer's [21] findings indicated that FSC grafts can differentiate into neurons, astrocytes, and oligodendrocytes at 5 weeks post-transplantation. In our study, however, the expression of 
the oligodendrocyte marker was very weak. This discrepancy could be due to different sexes of transplanted animal, lesion severity, and/or time points post-transplantation.

Several studies have demonstrated that mature host cells may migrate into the graft. For example, Zhou et al. [34] transplanted fetal cerebrocortical tissue into brains of newborn mice, and they observed the presence of host astrocytes within the graft. Moreover, Theele et al. [24] indicated that there was an extensive infiltration of microglia/macrophages and lymphocytes within FSC graft in nonimmunosuppressed inbred rats. These host immune responses may be involved in rejection of the graft [24] and/or support graft neovascularization [35]. Indeed, our data showed that some Iba1-positive cells within the graft may be derived from the host progenitor cells and/or invasion of mature host immune cells.

Gulino et al. [36] demonstrated that there were some acetylcholinesterase-positive elements within or around FSC-derived grafts after transplantation into volkesininduced motoneuron depleted animals. In addition, they found that the spinal extracellular acetylcholine level was partially restored in transplanted animals [36]. Our data demonstrated that FSC-derived graft neurons contained serotonin-, DBH-, and ChAT-positive cells, suggesting that graft neurons may have the potential to release neurotransmitters to modulate host and/or graft activity.

\section{Connection Between the Host and FSC Graft}

Both CT-B and WGA tracers have been used to investigate the neural control of the phrenic motor system [28, 37]. Our data indicate that phrenic motoneurons are robustly labeled by these tracers. Although there were some CT-B particles around the host-graft interface, we were unable to detect CT-B-labeled cells within the graft. This negative result suggests that FSCderived grafts did not directly innervate the diaphragm. However, we did observe a few WGA-positive cells within the graft, suggesting that graft neurons make minor connections with the host phrenic circuit through polysynaptic connections. Because the retrograde tracer was only applied on the diaphragm in the present study, the tracer can only label the phrenic motor system (e.g., the phrenic motoneuron and premotor neurons, which innervate the phrenic nucleus). Accordingly, only the graft neurons that have axons projecting to the phrenic motoneurons could be labeled by the retrograde tracer (i.e., WGA). As there were only a few WGA-labeled graft neurons observed within the graft region, we can only conclude that the graft tissue has a mild connection with the host phrenic motor system. However, we cannot exclude that the graft can integrate with the other host motor and/or sensory system. Although the graft used in the present study can express GFP, we did not detect robust GFP-positive fibers in the host region. The weak expression of GFP-positive fibers may be attributed to several factors: 1) the graft axons did not extensively project to the host tissue owing to the formation of the glia scar at the host-graft interface; 2) the graft neuronal axon did not express robust GFP as well as neuronal cell body or glial cell and therefore the innervation pattern of the graft axon may not be effectively revealed in the host tissue; 3 ) our current data demonstrated that the proportion of oligodendrocytes was very low in the graft, which may influence the graft axonal projection to the host tissue. Additionally, Buttry and Goshgarian [37] demonstrated that WGA conjugated with Alexa Fluor dyes may detect the activity state of the synapse and label the physiologically active pathway. This suggested that FSC-derived graft neurons may have a physiological impact on phrenic bursting. Indeed, from our data, phrenic bursting was relatively greater in FSCtransplanted animals than in $\mathrm{C} 4 \mathrm{Hx}$ animals.

The host-graft and graft-graft interaction was demonstrated by serotonin, DBH, GAD, and VGLUT2 immunoreactive fibers within the graft. Robust expression of GAD- and VGLUT2-positive fibers suggested that graft neurons could be influenced by $\gamma$-aminobutryic acid and glutamate, which may be released from the host and/or graft. A few serotoninand DBH-positive neurons were also found within the graft, suggesting the serotonergic and noradrenergic fibers within the graft could be partially derived from the graft itself. Several reports indicated that host serotonergic and noradrenergic fibers can grow into the FSC-derived graft [30, 38]. Therefore, the monoaminergic fibers within the graft could be also partially attributed to the growth and/or regeneration of host nerve fibers.

\section{The Impact of FSC Transplantation on Respiratory Motor Outputs}

The present study demonstrated that the ipsilateral phrenic burst amplitude was greater in $\mathrm{C} 4 \mathrm{Hx}+\mathrm{nFSC}$ animals than in $\mathrm{C} 4 \mathrm{Hx}+\mathrm{HBSS}$ animals during asphyxia, suggesting that FSC transplantation can modulate phrenic motor outputs. Several reports have indicated the presence of anatomic connections between FSC-derived grafts and the host phrenic circuit [26, 38] and our previous studies showed that activity of FSCderived graft neurons could be excited by hypoxic treatment $[26,39]$. This evidence suggests that FSC-derived graft neurons may excite phrenic motoneurons through polysynaptic transmission during asphyxia. In addition to the excitatory effect of graft, the improvement of phrenic activity could be due to the influence of the host circuit. Bregman [40] demonstrated that in newborn rats, host serotonergic fibers can grow into the graft and re-innervate the host spinal cord caudal to the injury. Although the capacity for axonal growth is relatively weaker in adult rats than in newborn rats [38], our recent study demonstrated that transplantation of fetal medullary cells can improve respiratory outputs in high-cervical hemisected rats [37]. These results indicated that fetal grafts may provide a trophic microenvironment that enables 
serotonergic fibers to grow through the transplant and/or grow around the host-graft interface to reach the ventral horn and then modulate phrenic motoneuron excitability.

Although phrenic recordings demonstrated that the ipsilateral phrenic burst amplitude under the anesthetized condition was improved in transplanted animals during asphyxia, the tidal volume of unanesthetized animals was not significantly different from that of $\mathrm{C} 4 \mathrm{Hx}+\mathrm{FSC}$ animals and $\mathrm{C} 4 \mathrm{Hx}+$ HBSS animals during normoxia or hypoxia. These data suggested that the effect of FSC transplantation on respiratory outputs might be revealed only under robust respiratory challenges. In addition, our recent report indicated that improvement of ipsilateral diaphragmatic outputs was not necessarily associated with increased tidal volume [41]. Accordingly, an increase of phrenic activity ipsilateral to the lesion may not be sufficient to modulate the overall respiratory behaviors of unanesthetized animals.

\section{Conclusion}

Our results indicate that a "component" of FSC shows promise for the repair of injured spinal cord and the promotion of respiratory recovery following mid-cervical spinal injury. Future transplantation studies should therefore consider using a cocktail of cellular resources, including neural stem cells, neural precursors, non-neural cells, cellular matrix, and growth factors, to reconstruct the injured spinal cord and restore function. Although the use of tissue grafts derived from fetal tissue could pose an ethical issue, this traditional approach of FSC transplantation represents an important proofof-concept model for advancing translational cellular replacement therapy (i.e., induced pluripotent stem cells).

Acknowledgements This work was supported by grants from the Ministry of Science and Technology (MOST 102-2320-B-110-004MY3 \& 105-2628-B-110-002-MY3), National Health Research Institutes (NHRI-EX105-10223NC), and NSYSU-KMU Joint Research Project (105-I004).

\section{Compliance with ethical standards}

Conflict of Interest The authors declare that the research was conducted in the absence of any commercial or financial relationships that could be construed as a potential conflict of interest.

\section{References}

1. Lane MA. Spinal respiratory motoneurons and interneurons. Respir Physiol Neurobiol 2011;179:3-13.

2. Goshgarian HG, Rafols JA. The phrenic nucleus of th albino rat: a correlative HRP and Golgi study. J Comp Neurol 1981;201:441456.
3. Dobbins EG, Feldman JL. Brainstem network controlling descending drive to phrenic motoneurons in rat. J Comp Neurol 1994;347: 64-86.

4. Duffin J. Functional organization of respiratory neurones: a brief review of current questions and speculations. Exp Physiol 2004;89: 517-529.

5. Lee KZ, Fuller DD. Neural control of phrenic motoneuron discharge. Respir Physiol Neurobiol 2011;179:71-79.

6. Winslow C, Rozovsky J. Effect of spinal cord injury on the respiratory system. Am J Phys Med Rehabil 2003;82:803-814.

7. Zimmer MB, Nantwi K, Goshgarian HG. Effect of spinal cord injury on the respiratory system: basic research and current clinical treatment options. J Spinal Cord Med 2007;30:319-330.

8. Smuder AJ, Gonzalez-Rothi EJ, Kwon OS, et al. Cervical spinal cord injury exacerbates ventilator-induced diaphragm dysfunction. J Appl Physiol (1985) 2016;120:166-177.

9. Schilero GJ, Spungen AM, Bauman WA, Radulovic M, Lesser M. Pulmonary function and spinal cord injury. Respir Physiol Neurobiol 2009;166:129-141.

10. Thuret S, Moon LD, Gage FH. Therapeutic interventions after spinal cord injury. Nat Rev Neurosci 2006;7:628-643.

11. Reier PJ, Golder FJ, Bolser DC, et al. Gray matter repair in the cervical spinal cord. Prog Brain Res 2002;137:49-70.

12. Tetzlaff W, Okon EB, Karimi-Abdolrezaee S, et al. A systematic review of cellular transplantation therapies for spinal cord injury. J Neurotrauma 2011;28:1611-1682.

13. Harrop JS, Hashimoto R, Norvell D, et al. Evaluation of clinical experience using cell-based therapies in patients with spinal cord injury: a systematic review. J Neurosurg Spine 2012;17(1 Suppl.): 230-246.

14. Sandhu MS, Ross HH, Lee KZ, Ormerod BK, Reier PJ, Fuller DD. Intraspinal transplantation of subventricular zone-derived neural progenitor cells improves phrenic motor output after high cervical spinal cord injury. Exp Neurol 2017;287:205-215.

15. Dougherty BJ, Gonzalez-Rothi EJ, Lee KZ, Ross HH, Reier PJ, Fuller DD. Respiratory outcomes after mid-cervical transplantation of embryonic medullary cells in rats with cervical spinal cord injury. Exp Neurol 2016;278:22-26.

16. Pajer K, Nemes C, Berzsenyi S, et al. Grafted murine induced pluripotent stem cells prevent death of injured rat motoneurons otherwise destined to die. Exp Neurol 2015;269:188-201.

17. Kuo HS, Tsai MJ, Huang MC, et al. Acid fibroblast growth factor and peripheral nerve grafts regulate Th2 cytokine expression, macrophage activation, polyamine synthesis, and neurotrophin expression in transected rat spinal cords. J Neurosci 2011;31:4137-4147.

18. Chung HJ, Chung WH, Lee JH, et al. Expression of neurotrophic factors in injured spinal cord after transplantation of humanumbilical cord blood stem cells in rats. J Vet Sci 2016;17:97-102.

19. Chow SY, Moul J, Tobias CA, et al. Characterization and intraspinal grafting of EGF/bFGF-dependent neurospheres derived from embryonic rat spinal cord. Brain Res 2000;874:87-106.

20. White TE, Lane MA, Sandhu MS, O'Steen BE, Fuller DD, Reier PJ. Neuronal progenitor transplantation and respiratory outcomes following upper cervical spinal cord injury in adult rats. Exp Neurol 2010;225:231-236.

21. Lepore AC, Fischer I. Lineage-restricted neural precursors survive, migrate, and differentiate following transplantation into the injured adult spinal cord. Exp Neurol 2005;194:230-242.

22. Medalha CC, Jin Y, Yamagami T, Haas C, Fischer I. Transplanting neural progenitors into a complete transection model of spinal cord injury. J Neurosci Res 2014;92:607-618.

23. Beaumont E, Houle JD, Peterson CA, Gardiner PF. Passive exercise and fetal spinal cord transplant both help to restore motoneuronal properties after spinal cord transection in rats. Muscle Nerve 2004;29:234-242. 
24. Theele DP, Schrimsher GW, Reier PJ. Comparison of the growth and fate of fetal spinal iso- and allografts in the adult rat injured spinal cord. Exp Neurol 1996;142:128-143.

25. Ribotta MG, Provencher J, Feraboli-Lohnherr D, Rossignol S, Privat A, Orsal D. Activation of locomotion in adult chronic spinal rats is achieved by transplantation of embryonic raphe cells reinnervating a precise lumbar level. J Neurosci 2000;20:5144-5152.

26. Lee KZ, Lane MA, Dougherty BJ, et al. Intraspinal transplantation and modulation of donor neuron electrophysiological activity. Exp Neurol 2014;251:47-57.

27. Lane MA, White TE, Coutts MA, et al. Cervical prephrenic interneurons in the normal and lesioned spinal cord of the adult rat. J Comp Neurol 2008;511:692-709.

28. Qiu K, Lane MA, Lee KZ, Reier PJ, Fuller DD. The phrenic motor nucleus in the adult mouse. Exp Neurol 2010;226:254-258.

29. Lee KZ, Kuo HC. Vagal control of breathing pattern after midcervical contusion in rats. J Neurotrauma 2016 Oct 13 [Epub ahead or print].

30. Reier PJ, Bregman BS, Wujek JR. Intraspinal transplantation of embryonic spinal cord tissue in neonatal and adult rats. J Comp Neurol 1986;247:275-296.

31. Bonner JF, Steward O. Repair of spinal cord injury with neuronal relays: From fetal grafts to neural stem cells. Brain Res 2015;1619: 115-123.

32. Coumans JV, Lin TT, Dai HN, et al. Axonal regeneration and functional recovery after complete spinal cord transection in rats by delayed treatment with transplants and neurotrophins. J Neurosci 2001;21:9334-9344.

33. Jakeman LB, Reier PJ, Bregman BS, et al. Differentiation of substantia gelatinosa-like regions in intraspinal and intracerebral transplants of embryonic spinal cord tissue in the rat. Exp Neurol 1989;103:17-33.

34. Zhou HF, Lund RD. Neonatal host astrocyte migration into xenogeneic cerebral cortical grafts. Brain Res Dev Brain Res 1992;65: 127-131.

35. Pennell NA, Streit WJ. Colonization of neural allografts by host microglial cells: relationship to graft neovascularization. Cell Transplant 1997;6:221-230.

36. Gulino R, Cataudella T, Casamenti F, Pepeu G, Stanzani S, Leanza G. Acetylcholine release from fetal tissue homotopically grafted to the motoneuron-depleted lumbar spinal cord. An in vivo microdialysis study in the awake rat. Exp Neurol 2007;204:326-338.

37. Buttry JL, Goshgarian HG. Injection of WGA-Alexa 488 into the ipsilateral hemidiaphragm of acutely and chronically $\mathrm{C} 2$ hemisected rats reveals activity-dependent synaptic plasticity in the respiratory motor pathways. Exp Neurol 2014;261:440-450.

38. Bregman BS, Kunkel-Bagden E, Reier PJ, Dai HN, McAtee M, Gao D. Recovery of function after spinal cord injury: mechanisms underlying transplant-mediated recovery of function differ after spinal cord injury in newborn and adult rats. Exp Neurol 1993;123:316.

39. Gonzalez-Rothi EJ, Lee KZ, Dale EA, Reier PJ, Mitchell GS, Fuller DD. Intermittent hypoxia and neurorehabilitation. J Appl Physiol (1985) 2015;119:1455-1465.

40. Bregman BS. Spinal cord transplants permit the growth of serotonergic axons across the site of neonatal spinal cord transection. Brain Res 1987;431:265-279.

41. Hsu SH, Lee KZ. Effects of serotonergic agents on respiratory recovery after cervical spinal injury. J Appl Physiol (1985) 2015;119:1075-1087. 